\title{
Relationships between Gulf of California Moisture Surges and Tropical Cyclones in the Eastern Pacific Basin
}

\author{
R. W. Higgins and W. SHI \\ NOAA/NWS/NCEP/Climate Prediction Center, Washington, D.C.
}

(Manuscript received 21 December 2004, in final form 17 May 2005)

\begin{abstract}
Relationships between Gulf of California moisture surges and tropical cyclones (TCs) in the eastern Pacific basin are examined. Standard surface observations are used to identify gulf surge events at Yuma, Arizona, for a multiyear (July-August 1979-2001) period. The surges are related to TCs using National Hurricane Center 6-hourly track data for the eastern Pacific basin. Climate Prediction Center (CPC)observed daily precipitation analyses and the NCEP Regional Reanalysis are used to examine the relative differences in the precipitation, atmospheric circulation, and moisture fields for several categories of surge events, including those that are directly related to TCs, indirectly related to TCs, and not related to TCs.

It is shown that the response to the surge in the southwestern United States and northwestern Mexico is strongly discriminated by the presence or absence of TCs. Surges related to TCs tend to be associated with much stronger and deeper low-level southerly flow, deeper plumes of tropical moisture, and wetter conditions over the core monsoon region than surges that are unrelated to TCs. The response to the surge is also strongly influenced by the proximity of the TC to the Gulf of California (GOC) region. Tropical cyclones that track toward the GOC region exert a stronger, more direct influence on Yuma surges than those that track away from the GOC.
\end{abstract}

\section{Introduction}

Northward surges of relatively cool, moist maritime air from the eastern tropical Pacific into the southwestern United States via the Gulf of California (GOC) are common during the North American summer monsoon season (e.g., Hales 1972; Brenner 1974; Stensrud et al. 1997; Adams and Comrie 1997; Douglas and Leal 2003; Higgins et al. 2004a). These events, referred to as gulf or moisture surges in the literature, are related to the amount of convective activity and precipitation in northwestern Mexico and portions of the southwestern United States, including Arizona and New Mexico. Typical characteristics of gulf surges have been discussed in all of the studies referenced above, so it will be assumed that the reader is familiar with these.

Hales (1972) and Brenner (1974) used surface, radiosonde, and satellite observations, with some radar data, to identify unique features of the surges (e.g., surface

Corresponding author address: Dr. R. W. Higgins, Analysis Branch, Climate Prediction Center, NOAA/NWS/NCEP, 5200 Auth Rd., Camp Springs, MD 20746.

E-mail: Wayne.Higgins@noaa.gov weather changes, depth of the moist plumes, sources of moisture, evolution of the cloud mass, changes in thunderstorm activity) and possible factors in their development, including easterly waves. Stensrud et al. (1997) showed that the detailed characteristics of surges could be reproduced by a mesoscale numerical model. Recent diagnostic and modeling studies of gulf surges have emphasized their relationships to tropical storms south of Baja California, tropical easterly waves, and midlatitude westerly waves (e.g., Fuller and Stensrud 2000; Anderson et al. 2000).

The development of southerly low-level jets (LLJs) over the northern GOC region during the monsoon season has been linked to gulf surges in field campaigns (e.g., Meitin et al. 1991; Reyes et al. 1994; Higgins et al. 2004b) and in diagnostic and modeling studies (e.g., Douglas 1995; Douglas and Li 1996; Stensrud et al. 1997; Anderson et al. 2000). The GOC LLJ is one of the primary mechanisms by which moisture is transported from the northern GOC into the northern Sonoran Desert (e.g., Fawcett et al. 2002).

In a recent study Higgins et al. (2004a) examined relationships between moisture surges at Yuma, Arizona, and precipitation in the southwestern United 
States for several categories of surge events, including those that were relatively strong (weak) and those that were accompanied by relatively wet (dry) conditions in Arizona and New Mexico after onset. They showed that the occurrence of wet versus dry surges in this region was not discriminated by tropical easterly waves or midlatitude westerly waves, but rather by the relative location of the monsoon anticyclone in midlatitudes at the time of the gulf surge. In particular, during wet surges the axis of the monsoon anticyclone was typically located to the east of the monsoon region, permitting a deep layer of tropical moisture to be advected into Arizona and New Mexico from the south and east. During dry surges, the axis of the monsoon anticyclone was located to the west of the monsoon region, permitting midtropospheric northerly flow around the east side of the monsoon anticyclone to cap the atmosphere, inhibiting convective development even when a shallow, moist southerly flow was present near the surface.

While the results of Higgins et al. (2004a) may help explain the response to surges in Arizona and New Mexico, they do not elucidate how the responses might be affected by particular types of tropical disturbances (e.g., tropical cyclones, upper-level inverted troughs, etc.). An examination of the individual cases that make up the composites in their study (not shown) indicates that further classification of the surge events based on their relationships to tropical cyclones (hereafter TCs) might greatly enhance our understanding of the response to the surges in southwestern North America. In fact, roughly half of the surges in the Higgins et al. (2004a) study occurred within 3 days of a TC crossing $110^{\circ} \mathrm{W}$ (see below).

Recent studies by Englehart and Douglas (2001) and Gutzler and Ritchie (2004) have shown that eastern Pacific TCs are important sources of precipitation for southwestern North America. However, to our knowledge, there have been no systematic investigations of relationships between eastern Pacific TCs and GOC surge events and, consequently, of relationships between the TCs and the responses to the surges in southwestern North America.

The primary objective of this study is to examine spatial and temporal relationships between GOC moisture surges and TCs in the eastern Pacific basin. Standard surface observations are used to identify gulf surge events at Yuma, Arizona, for a multiyear (JulyAugust 1979-2001) period. As in previous studies (e.g., Fuller and Stensrud 2000), the surge events are identified using hourly surface observations of dewpoint temperature, wind direction, and wind speed. The surges are related to TCs using National Hurricane Center 6-hourly track data for the eastern Pacific basin. National Centers for Environmental Prediction/Climate Prediction Center (NCEP/CPC)-observed daily precipitation analyses and the NCEP Regional Reanalysis are used to examine the relative differences in the precipitation, atmospheric circulation, and moisture fields in southwestern North America for several categories of surge events, including those that are directly related to TCs, indirectly related to TCs, and not related to TCs.

Many surges in the GOC region occur in response to mesoscale convective systems over the coastal plains of western Mexico that generate low-level convective outflows over the GOC that strengthen the low-level southerly flow (e.g., Higgins et al. 2004b). However, in this study the focus is on relationships between TCs and surges, without regard to the possibly important role of the intervening mesoscale convective system events. We recognize that this is an important aspect of the problem that should be considered in future studies.

A discussion of the datasets and the method used to identify surge events is found in section 2 . The ability of the NCEP Regional Reanalysis to reproduce the tropical cyclone tracks found in observations is examined in section 3. Relationships between Yuma surge events and TCs are discussed in section 4 with emphasis on differences in the large-scale circulation, moisture, and precipitation fields for surges that are related to TCs versus those that are not. A brief summary and discussion of future plans are given in section 5 .

\section{Data and methods}

As in our previous study (Higgins et al. 2004a) we employ hourly surface observations of dewpoint temperature, wind speed, and wind direction at Yuma, Arizona, to identify gulf surge events. These events are identified during both July and August for a 23-yr period, 1979-2001 (data prior to 1979 are not used in this study to be consistent with the Regional Reanalysis dataset, which is unavailable prior to 1979). The daily precipitation analysis is obtained from CPC's Unified Precipitation Database (Higgins et al. 2000) together with additional daily data from the Mexican Weather Service. Daily data are gridded to a horizontal resolution of $1^{\circ}$ latitude $\times 1^{\circ}$ longitude and are available for a multiyear (1948-present) period. Sea level pressure and zonal and meridional wind and moisture fields at various tropospheric levels are from the NCEP Regional Reanalysis (RR) dataset (Mesinger et al. 2005, hereafter MBAMS). The RR dataset is a multiyear 
(1979-2003) homogenous mesoscale regional analysis performed with a fixed data assimilation system [previous reanalysis efforts such as the NCEP-NCAR global reanalysis of Kalnay et al. (1996) have used fixed assimilation systems] for North America and adjacent oceanic areas. The model used is the 2003 version of the NCEP Eta Model, which has a horizontal resolution of $32 \mathrm{~km}$ and 45 layers in the vertical. The RR data are shown to be representative of the local climate based on a validation of TC trajectories, as discussed in section 3.

Tropical cyclone track data are from the Atlantic and Northeast Pacific Tropical Cyclone (HURDAT) dataset of the National Hurricane Center (Neumann et al. 1999). This dataset contains 6-hourly records of the locations and intensities for all tropical storms and hurricanes from 1950 to present. In this study the term tropical cyclone refers to all tropical storms (sustained winds $>39 \mathrm{kt}$ or $17 \mathrm{~m} \mathrm{~s}^{-1}$ ) and hurricanes (sustained winds $>74 \mathrm{mi} \mathrm{h}^{-1}$ or $33 \mathrm{~m} \mathrm{~s}^{-1}$ ) in the eastern Pacific basin.

Surface observations were used to identify gulf surge events at Yuma, Arizona, during July-August 19792001 (we note that surface observations were missing during July-August 1992). The TC track data were also available over this period. Time series for the RR and observed precipitation fields were constructed for the period July-August 1979-2001, and circulation and precipitation composites were made over this period. Anomalies are defined as departures from base period (1979-2001) mean daily values.

Statistical significance tests were performed on each anomaly pattern and are shown below (Figs. 3-13). Though grayscale shading was assigned according to fixed intervals, the anomalies represented by shading were for the most part significant at the $95 \%$ confidence level (there were some exceptions for small anomalies several days before or after the onset date of the Yuma surges). Since the discussion focuses on the strongest anomalies, the results of the significance tests are not shown in order to avoid unnecessary clutter in the figures.

\section{Identification of surges}

Surges were identified using the method of Fuller and Stensrud (2000), but with modifications as discussed in section 2a of Higgins et al. (2004a). Hourly observations of surface dewpoint temperature, wind direction, and wind speed from Yuma are used to diagnose the occurrence of surges during the period JulyAugust 1979-2001 [we use a slightly shorter period than in Higgins et al. (2004a) to be consistent with other
TABLE 1. Number (fraction in percent) of total surge events at Yuma that were TC related and not TC related during the period July-August 1979-2001. Yuma surges are further subdivided into those with direct (indirect) relationships to TCs (see text for definitions of the categories).

\begin{tabular}{lc}
\hline \multicolumn{1}{c}{ Category } & Number of events \\
\hline All & 132 \\
TC related & $65(49 \%)$ \\
Not related to TCs & $67(51 \%)$ \\
Direct & $38(58 \%$ of TC related) \\
Indirect & $27(42 \%$ of TC related $)$ \\
\hline
\end{tabular}

datasets as described below]. July and August are chosen because these are the two months when the summer monsoon season is most active (e.g., Douglas et al. 1993). A 25-h running mean is applied to the hourly dewpoint, wind direction, and wind speed data, prior to the identification of surge events at Yuma and Tucson. While this provides a slight smoothing to the data, it has almost no impact on the identification of individual surge events (see Higgins et al. 2004a for details).

Fuller and Stensrud (2000) identified days of surge onset as those with rapid increases in surface dewpoint temperature after which the maximum daily dewpoint temperature remains at or above $15.7^{\circ} \mathrm{C}$ at Yuma for at least several days. In addition, they also required the surface wind speeds on the day of the rapid dewpoint temperature rise to be greater than $4 \mathrm{~m} \mathrm{~s}^{-1}$ for at least one reporting time and for the surface wind direction to be between $150^{\circ}$ and $210^{\circ}$. Here we apply their criteria to the 25 -h running mean dewpoint temperature time series, but with a few minor modifications (Higgins et al. 2004a, section 2a). Comparisons of the 25-h running mean dewpoint temperature, wind speed, and wind direction time series at Yuma for July-August 1986 to hourly time series used in Fuller and Stensrud (2000) (see Fig. 1 of Higgins et al. 2004a) showed that the same set of events are identified using the modified time series as described above.

During the period analyzed (July-August 1979-2001 except for 1992) a total of 132 surges are identified at Yuma for an average of roughly three surges per month. In this study the surges are further classified based on their relationships to eastern Pacific TCs. In particular, if a TC (as identified in the NHC track dataset) crossed $110^{\circ} \mathrm{W}$ within 3 days of a Yuma surge, then it was considered to be a TC-related surge. Sixtyfive of the 132 Yuma surge events were found to be related to TCs (Table 1). The remaining 67 cases are considered to be unrelated to eastern Pacific TCs. We note that a few cases in this latter category may be related to TCs in the western Atlantic basin, but this was not considered in this study. 
TABLE 2. Number (fraction in percent) of TC-related, non-TCrelated, direct, and indirect surge events at Yuma during the period July-August 1979-2001 that were strong and wet, strong and dry, weak and wet, or weak and dry [see text for definitions of the strong, weak, wet, and dry categories, which are also discussed in detail in Higgins et al. (2004a)].

\begin{tabular}{|c|c|c|c|c|}
\hline Category & $\begin{array}{l}\mathrm{TC} \\
\text { related }\end{array}$ & $\begin{array}{l}\text { Not TC } \\
\text { related }\end{array}$ & Direct & Indirect \\
\hline Strong and wet & $29(45 \%)$ & $18(27 \%)$ & $19(50 \%)$ & $10(37 \%)$ \\
\hline Strong and dry & $17(26 \%)$ & $12(18 \%)$ & $12(32 \%)$ & $5(19 \%)$ \\
\hline Weak and wet & $9(14 \%)$ & $15(22 \%)$ & $4(10 \%)$ & $5(19 \%)$ \\
\hline Weak and dry & $10(15 \%)$ & $22(33 \%)$ & $3(8 \%)$ & $7(25 \%)$ \\
\hline
\end{tabular}

For compositing purposes, the TC-related surge cases were further subdivided into those with a direct (indirect) influence on the Yuma surges (Table 1). To make this procedure objective, eastern Pacific TCs are said to have a direct influence if the TC center of circulation moves northwestward or northward to within $3^{\circ}$ of Baja California, the GOC, or the Mexican mainland (poleward of $22^{\circ} \mathrm{N}$ ) during the 3-day period prior to the onset of a Yuma surge. All other TC-related surge cases have an indirect influence. Most TCs in this latter category simply continued to the west or westnorthwest across the eastern tropical Pacific, but too far south to have a direct influence. For each case in Table 1 we also examined animations of $925-\mathrm{hPa}$ vector wind and specific humidity from the Regional Reanalysis (MBAMS) to ensure that the direct versus indirect classification was appropriate. Comparisons of the TC track data in the RR and in the NHC datasets are favorable (see section 3 ).

As in Higgins et al. (2004a), we identified strong and weak surges by examining the change in dewpoint temperature over the 3 days after surge onset. If the $25-\mathrm{h}$ running mean dewpoint temperature decreases during this 3-day period, then the surge is categorized as weak. In contrast, if the dewpoint temperature increases during this 3-day period, then the surge is categorized as being strong. As noted in Fuller and Stensrud (2000), this taxonomy is more closely associated with the duration of a surge than with any initial change in moisture associated with the surge leading edge. In addition, as in Higgins et al. (2004a) we define wet (dry) surge events as those with positive (negative) precipitation anomalies in eastern Arizona and western New Mexico $\left(32^{\circ}-36^{\circ} \mathrm{N}, 112 .{ }^{\circ} 5-107.5^{\circ} \mathrm{W}\right)$, hereafter AZNM, for the 5 -day period (day 0 to day +4 ) after onset. At Yuma we find that $45 \%$ of the TC-related surges are strong and wet, while only $27 \%$ of the surges with no relationship to TCs are strong and wet (Table 2). Half of the surges with a direct relationship to TCs are strong and wet, while $82 \%$ are strong (Table 2).

\section{Tropical cyclone tracks}

Observed TC track data from the HURDAT dataset (Neumann et al. 1999) is used to relate TCs to Yuma surges. Direct and indirect cases are selected using the criterion discussed in the previous section. In section 4 the Regional Reanalysis is used to relate the circulation and moisture fields to TCs for the direct and indirect cases. To have confidence in these results, however, the Regional Reanalysis must have a reasonably good representation of the spatial and temporal evolution of the TCs (and associated circulation and moisture fields) found in observations. The individual tracks for all of the TC-related surges as captured by the Regional Reanalysis as well as the mean tracks for both direct and indirect cases in the Regional Reanalysis and in observations are shown in Fig. 1. The TC center locations and intensities are based on daily minimum central pressures and daily maximum surface wind speeds. Mean positions of the TCs in the Regional Reanalysis and in observations for both direct and indirect cases are shown from day -3 to day +3 relative to the onset of Yuma surges. The mean positions for direct and indirect cases are given in Tables 3 and 4, respectively. Overall, the RR has realistic TC tracks that compare well to observations, with a slight southward shift of the mean position relative to observations. The results indicate that it is appropriate to use the circulation and moisture fields from RR to link the TCs and surges at Yuma.

\section{Surge characteristics}

The North American Monsoon Experiment (NAME) 2004 field campaign (Higgins et al. 2004b) presented a unique opportunity to study TC-moisture surgeprecipitation relationships in the GOC region. The campaign featured observing system enhancements for monitoring and measuring moisture surge events including atmospheric profiling (radiosondes, pilot balloons, and wind profilers) along the GOC as well as rain gauge and radar data over western and northern Mexico. Ten intensive observing periods (IOPs) were carried out during the campaign. IOP 2 (0000 UTC 12 July-0000 UTC 15 July 2004) focused on the influence of Tropical Storm Blas on a GOC surge event. Johnson et al. (2004) noted these surge characteristics:

- a stage set by a strong north-south pressure gradient (heat low over the southwestern United States and pressure rises near the southern end of the GOC);

- increased easterly flow in northwestern Mexico leading to storms moving off the Sierra Madre Occidental (SMO), with convective downdraft outflows, followed by surges in the central and northern GOC; 


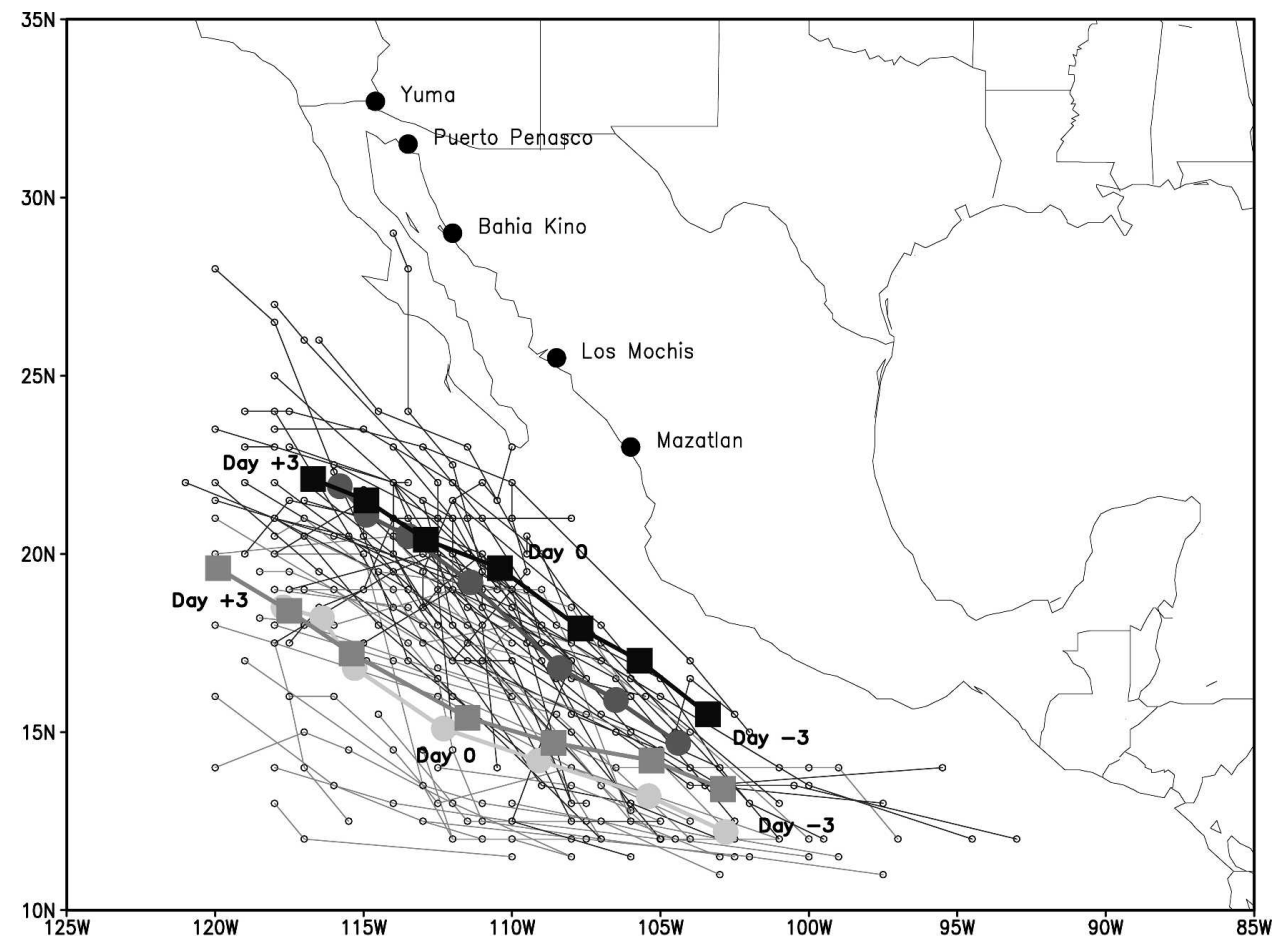

FIG. 1. Tropical cyclone tracks for storms within 3 days of onset of Yuma surges from the NCEP Regional Reanalysis (RR). Individual TCs with a direct (indirect) relationship to Yuma surges are indicated by dark (light) thin lines. The mean tracks from the RR for direct (indirect) cases are indicated by thick lines with dark (light) filled circles. Similarly, the mean tracks from observations for direct (indirect) cases are indicated by thick lines with dark (light) filled squares. The day relative to onset is indicated along the mean tracks. Several key sites referenced in the paper are indicated in the figure.

- pressure rises of approximately $6 \mathrm{hPa}$ over an $8-10-\mathrm{h}$ period during the surge; a $2^{\circ}-3^{\circ} \mathrm{C}$ temperature drop and a pressure rise signal moving rapidly up the GOC at speeds of approximately $25 \mathrm{~m} \mathrm{~s}^{-1}$;

- peak surge winds near $1 \mathrm{~km}$ above the ground with maximum winds of $20 \mathrm{~m} \mathrm{~s}^{-1}$ at Puerto Penasco, Mexico, and shallow convective outflows with peak winds near $300 \mathrm{~m}$ above the ground;

- surge leading to increases in total precipitable water and rainfall over northwestern Mexico and southern and eastern Arizona.

TABLE 3. Mean positions of TCs with a direct relationship to Yuma surges.

\begin{tabular}{lccccc}
\hline \hline & \multicolumn{2}{c}{ Observations } & & \multicolumn{2}{c}{ Regional reanalysis } \\
\cline { 2 - 3 } \cline { 5 - 6 } & Lat $\left({ }^{\circ} \mathrm{N}\right)$ & Lon $\left({ }^{\circ} \mathrm{W}\right)$ & & Lat $\left({ }^{\circ} \mathrm{N}\right)$ & Lon $\left({ }^{\circ} \mathrm{W}\right)$ \\
\hline Day -3 & 15.5 & 103.4 & & 14.7 & 104.4 \\
Day -2 & 17.0 & 105.7 & & 15.9 & 106.5 \\
Day -1 & 17.9 & 107.7 & & 16.8 & 108.4 \\
Day 0 & 19.6 & 110.4 & & 19.2 & 111.4 \\
Day +1 & 20.4 & 112.9 & & 20.5 & 113.5 \\
Day +2 & 21.5 & 114.9 & & 21.1 & 114.9 \\
Day +3 & 22.1 & 116.7 & & 21.9 & 115.8 \\
\hline
\end{tabular}

The evolution of the observed precipitation and precipitation anomalies relative to the onset of the 13 July 2004 surge (defined as day 0) at Yuma is shown in Fig. 2. The progression of enhanced precipitation along the west coast of Mexico and into the Southwest is clearly evident. Precipitation increased over much of the intermountain west in the days following surge onset.

In this section we examine whether the characteristics of the surge that occurred during July 2004 are compatible with those in composites based on the 19792001 Regional Reanalysis and observed precipitation

TABLE 4. Mean positions of TCs with an indirect relationship to Yuma surges.

\begin{tabular}{lccccc}
\hline \hline & \multicolumn{2}{c}{ Observation } & & \multicolumn{2}{c}{ Regional reanalysis } \\
\cline { 2 - 3 } & Lat $\left({ }^{\circ} \mathrm{N}\right)$ & Lon $\left({ }^{\circ} \mathrm{W}\right)$ & & Lat $\left({ }^{\circ} \mathrm{N}\right)$ & Lon $\left({ }^{\circ} \mathrm{W}\right)$ \\
\hline Day -3 & 13.4 & 102.9 & & 12.2 & 102.8 \\
Day -2 & 14.2 & 105.3 & & 13.2 & 105.4 \\
Day -1 & 14.7 & 108.6 & & 14.2 & 109.1 \\
Day 0 & 15.4 & 111.5 & & 15.1 & 112.3 \\
Day +1 & 17.2 & 115.4 & & 16.8 & 115.3 \\
Day +2 & 18.4 & 117.5 & & 18.2 & 116.4 \\
Day +3 & 19.6 & 119.9 & & 18.5 & 117.7 \\
\hline
\end{tabular}


(a) Accum. Precip.
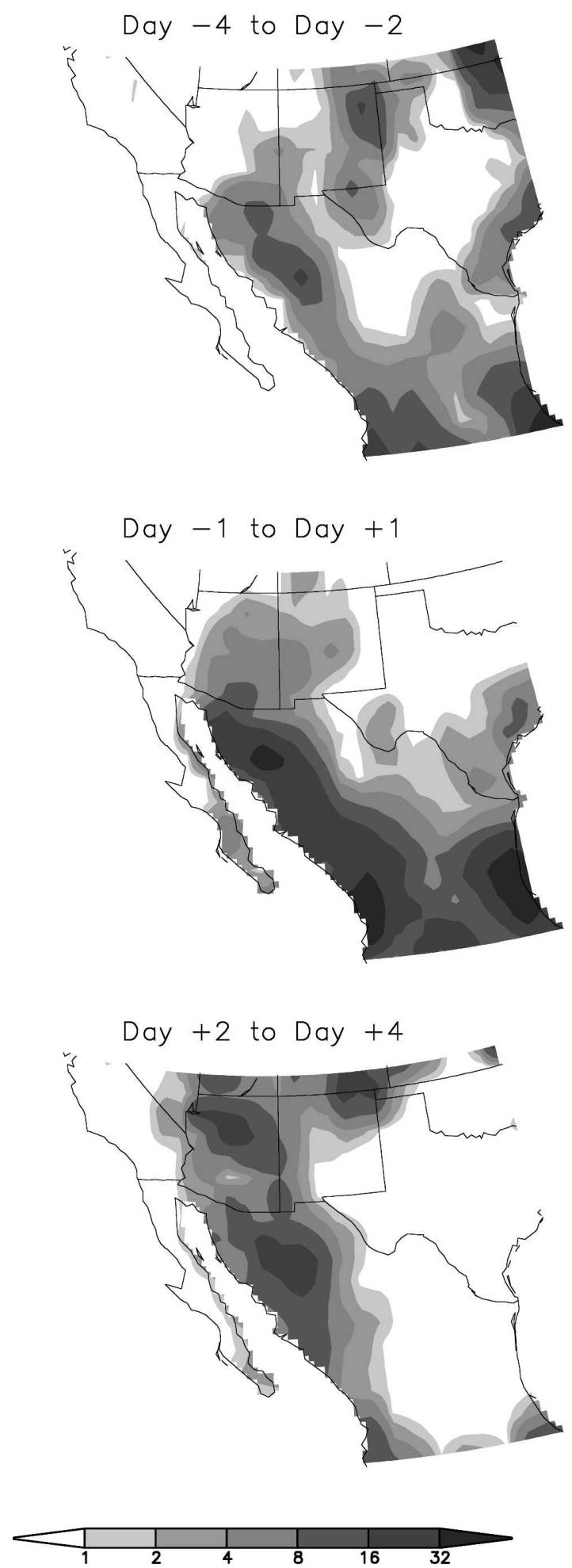

FIG. 2. Evolution of (a) accumulated precipitation ( $\mathrm{mm}$ ) and (b) accumulated precipitation anomalies (mm) for the $13 \mathrm{Jul} 2004 \mathrm{surge}$ at Yuma. Day 0 is the onset date of the surge at Yuma. The accumulation period relative to onset is indicated in each panel. The shading intervals are given by the color bar.

(b) Accum. Precip. Anom.
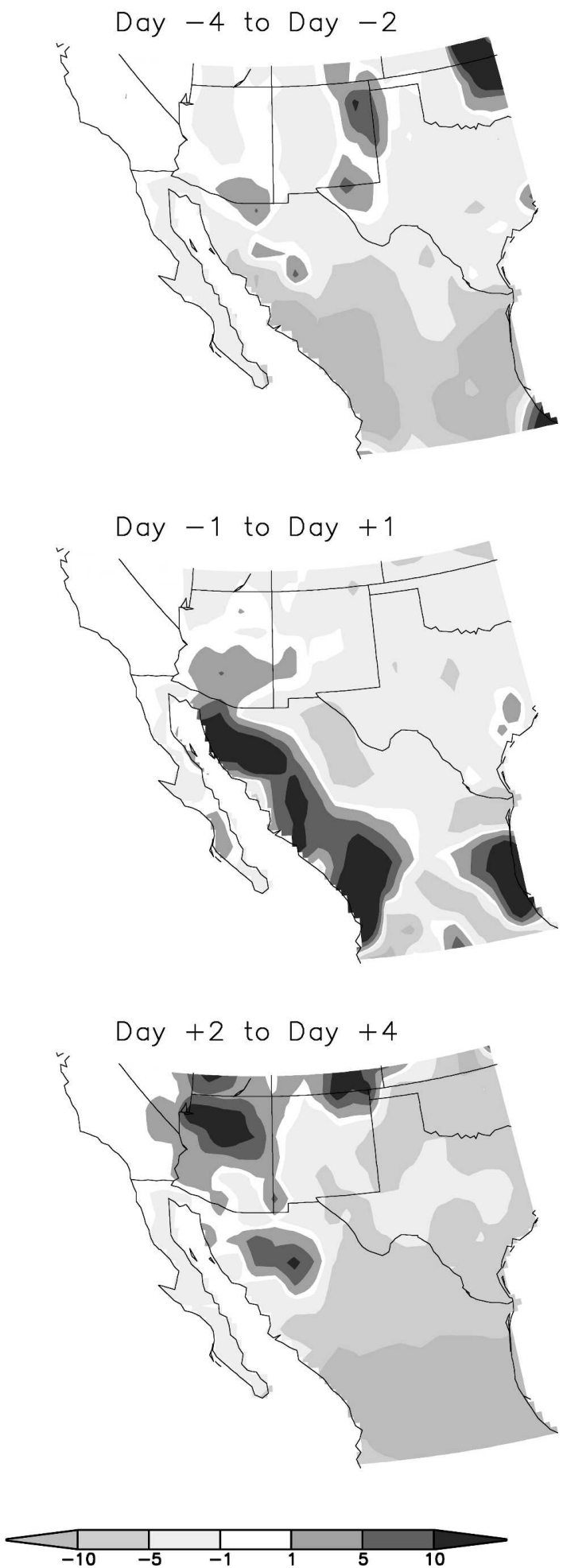

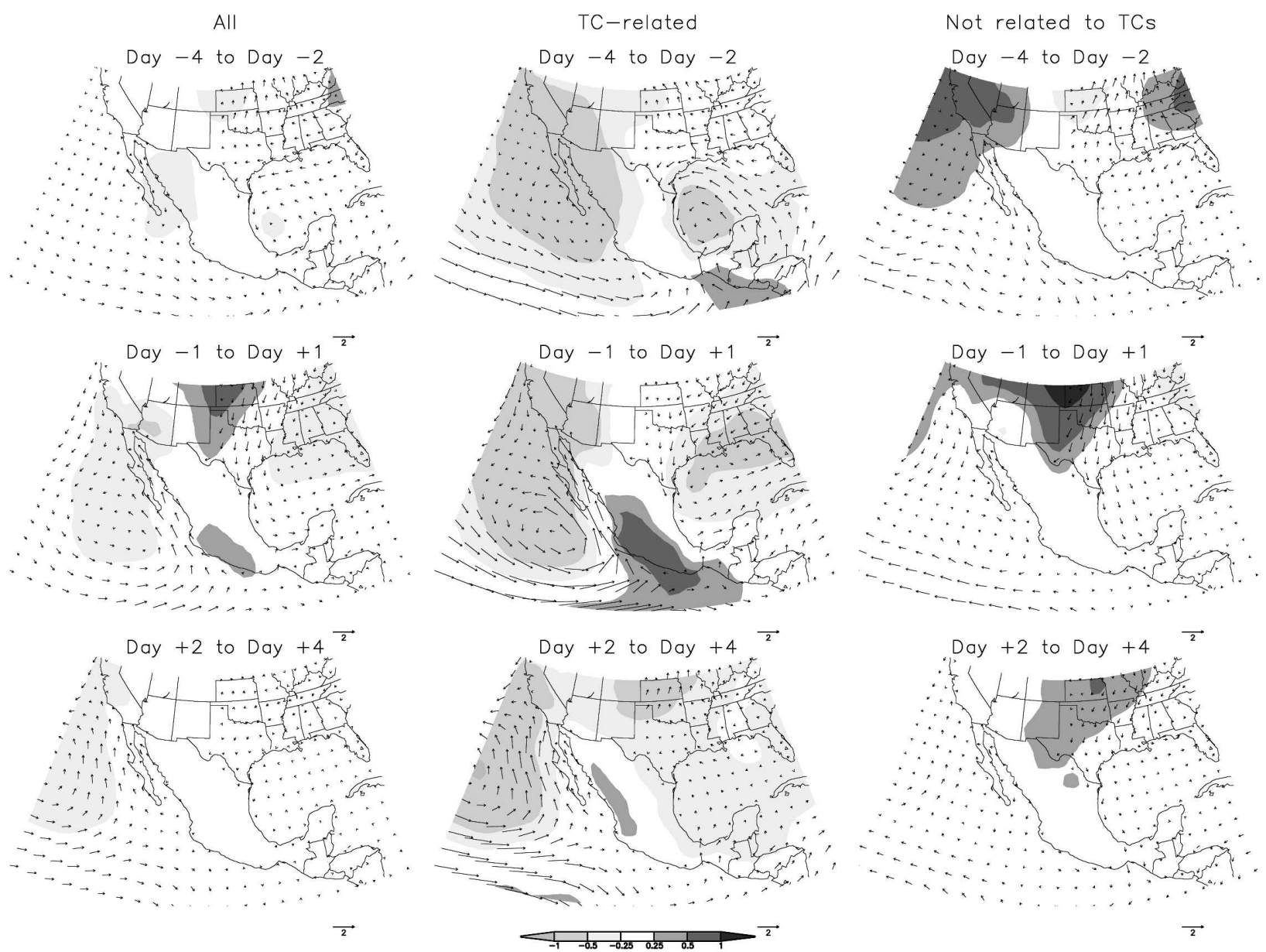

FIG. 3. Composite evolution of mean sea level pressure anomalies (hPa) and 925-hPa wind anomalies for (a) all surges, (b) TC-related surges, and (c) surges not related to TCs. Surges are keyed to Yuma. Day 0 is the onset date of the surges at Yuma. The averaging period relative to onset is indicated in each panel. The shading intervals for sea level pressure anomalies are given by the color bar. The number of cases in each composite is given in Table 1.

data. The general results presented here will be used in the future for more in depth study of the relevant dynamics and key phenomenological processes. This will include further examination of the individual cases in the composites.

\section{a. Mean sea level pressure patterns}

The composite evolution of mean sea level pressure anomalies together with $925-\mathrm{hPa}$ wind anomalies for all surges, TC-related surges, and TC-unrelated surges was examined (Fig. 3). A weak northwest-southeast pressure gradient is evident for the composite based on all surges (Fig. 3a). This signal is primarily due to the TCrelated surges (Fig. 3b), which are characterized by anomalous low pressure (heat low) centered over the southwestern United States, anomalous low pressure associated with the TC to the west or southwest of Baja California, and pressure rises near the southern end of the GOC. Yuma surges that are not related to TCs (Fig. 3c) have anomalous high pressure over the western United States that intensifies and shifts to the northeast during the evolution.

For reference, we also show the anomalous lowertropospheric $(925 \mathrm{hPa})$ winds, which indicate anomalous southeasterly flow along the GOC, especially for the TC-related cases (Fig. 3b). The distribution of anomalous low-level winds along the GOC is consistent with the anomalous pressure pattern in a geostrophic sense in which the winds blow along the pressure gradient discussed above. In contrast, anomalous southeasterly flow is not clearly evident in the cases that are not related to TCs (Fig. 3c), although more careful consideration of the daily composites does show weak anomalous southeasterly flow on days 0 and +1 (see Figs. $7 \mathrm{c}$ and $8 \mathrm{~b}$ ).

The northwest-southeast pressure gradient in the 

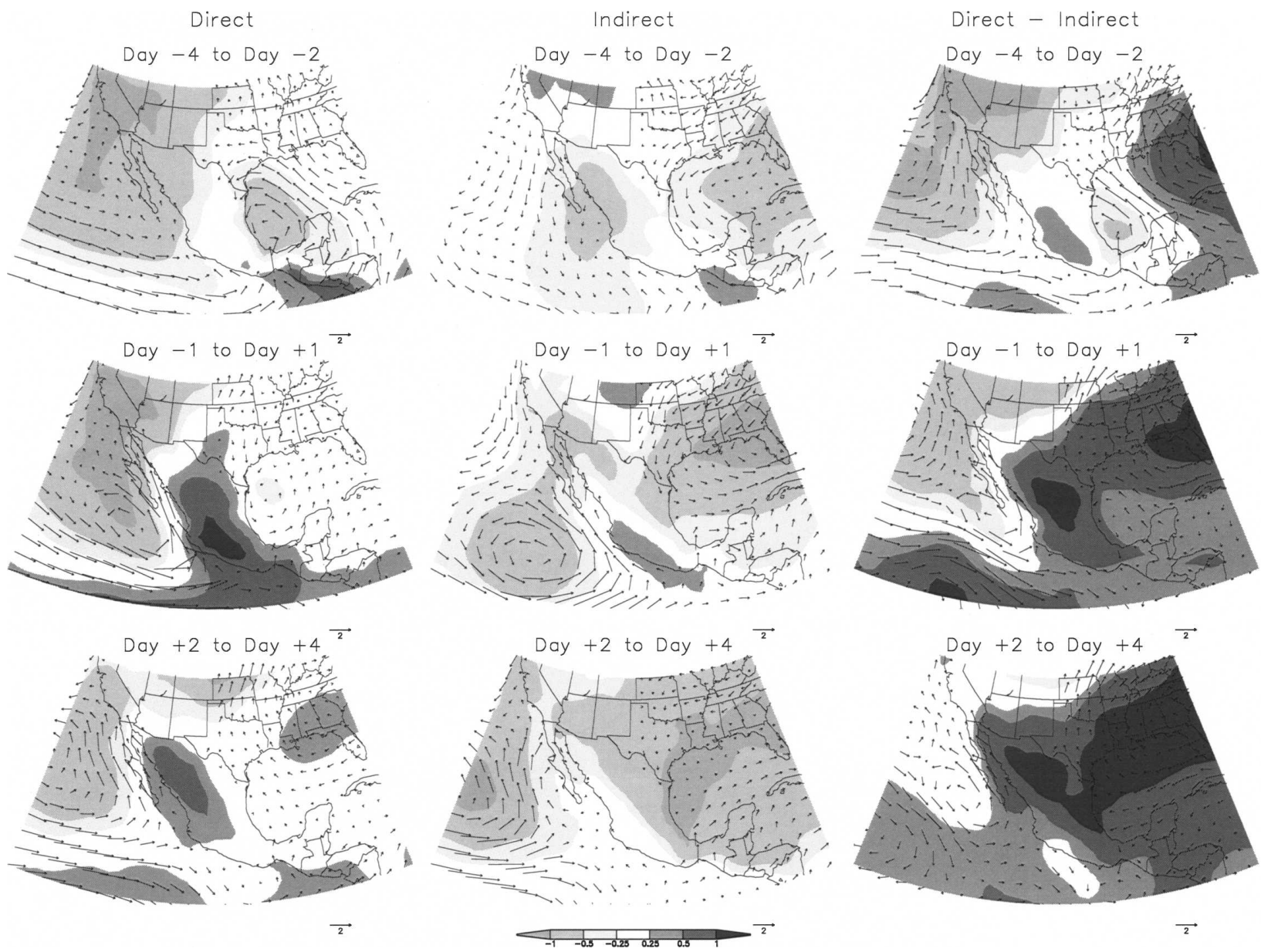

FIG. 4. Composite evolution of mean sea level pressure anomalies (hPa) and 925-hPa wind anomalies for Yuma surges with (a) direct, (b) indirect, and (c) direct minus indirect relationships to TCs. Surges are keyed to Yuma: day 0 is the onset date of the surges. The averaging period relative to onset is indicated in each panel. The shading intervals for SLP anomalies are given by the color bar. The number of cases in each composite is given in Table 1.

GOC region is strongest for Yuma surges with a direct relationship to TCs (Fig. 4a). Anomalous high pressure shifts to the north during the evolution, covering most of Mexico during and after onset. Pressure differences between the northern and southern GOC are roughly 1 $\mathrm{hPa}$, which is smaller but in the same sense as the NAME IOP 2 case. These features are also present for Yuma surges with an indirect relationship to TCs (Fig. $4 b)$ though they are weaker.

For the direct surges the pressure rise signal persists for roughly 4 days after onset at central and northern GOC locations (Fig. 4a), consistent with the observation that pressure "rises to a new level" and then stays there following the passage of the surge. The period over which pressure rises occur in the composites is readily determined from the SLP difference between the southern and northern GOC (see section 4b). For the direct cases the North Atlantic subtropical anticy- clone is relatively stronger and extended farther to the west than for the indirect cases (Fig. 4c).

\section{b. Circulation and moisture fields}

The composite evolution of 700-hPa wind and specific humidity anomalies for all TC-related and TCunrelated surges (Fig. 5) is characterized by anomalous easterly flow and moisture over northwestern Mexico, the GOC, and Baja California during the onset period, especially for the TC-related surges (Fig. 5b). This is consistent with the observation during NAME IOP 2 that increased easterly flow led to an increase in storms moving off the SMO in northwestern Mexico (with associated convective downdraft outflows), hence to an increase in precipitation in the core monsoon region. The anomalous moisture at $700 \mathrm{hPa}$ (and below) is more widespread in the TC-related cases (Fig. 5b) than in the cases that are not related to TCs (Fig. 5c). 
(a) All
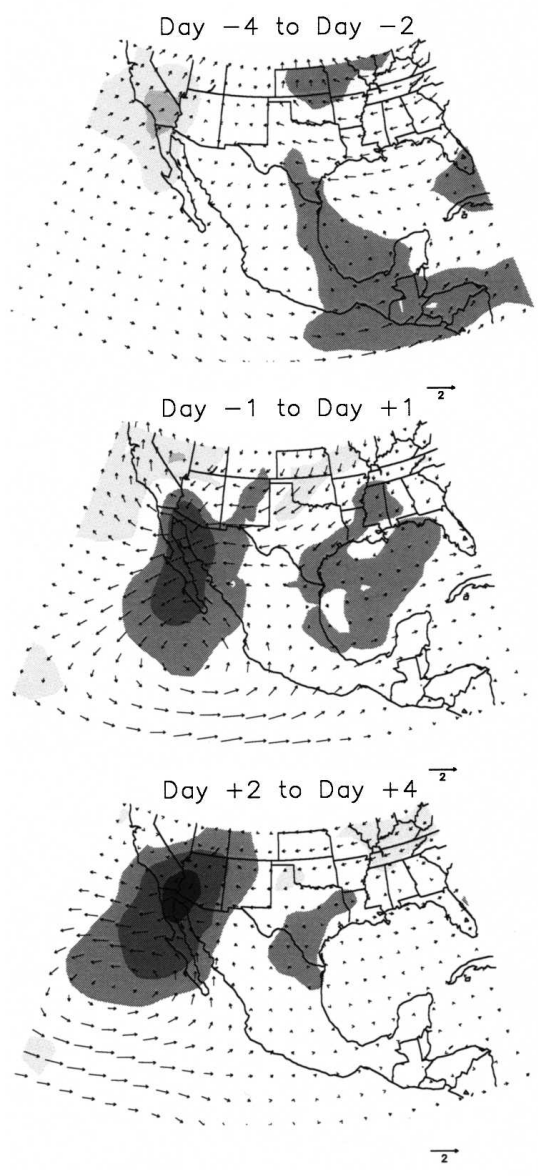

(b) TC-Related
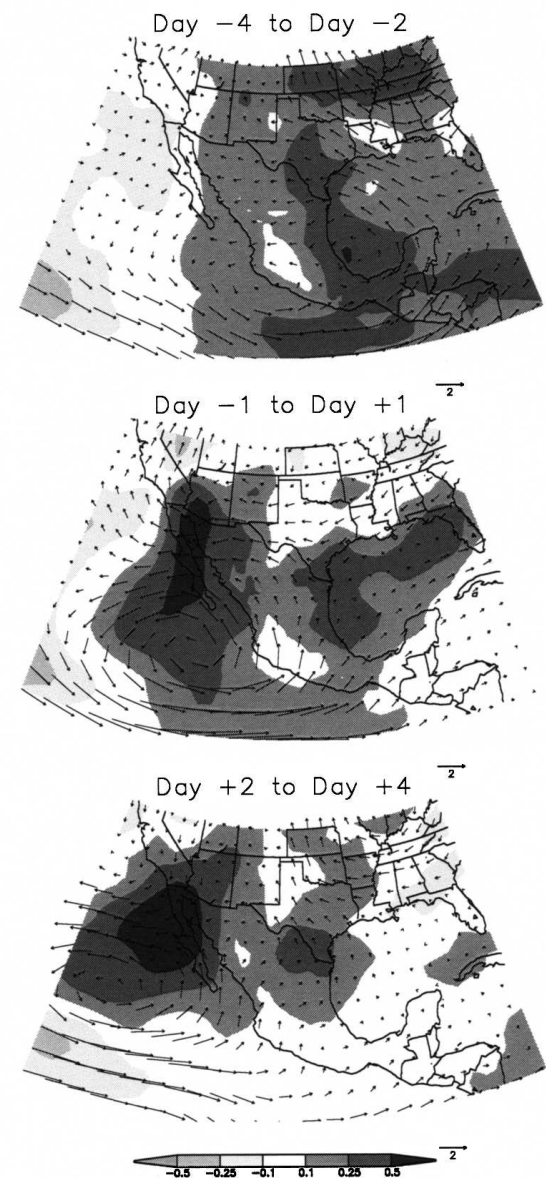

(c) Not Related to TCs

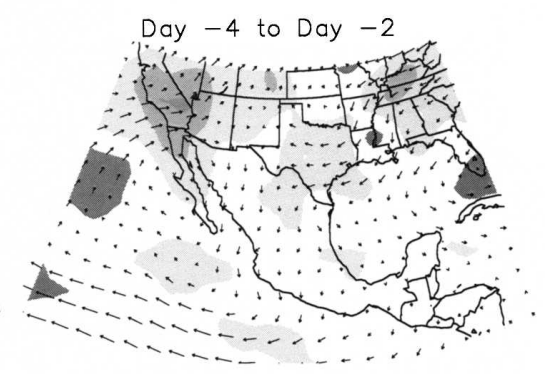

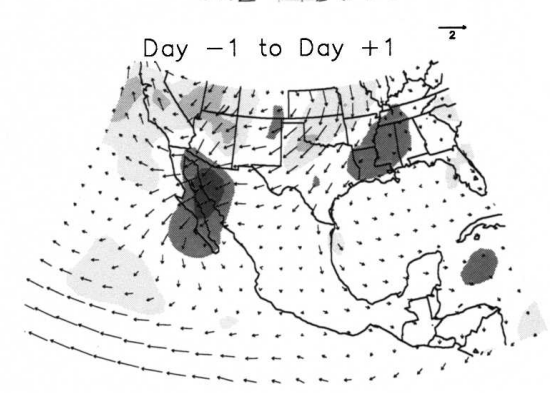

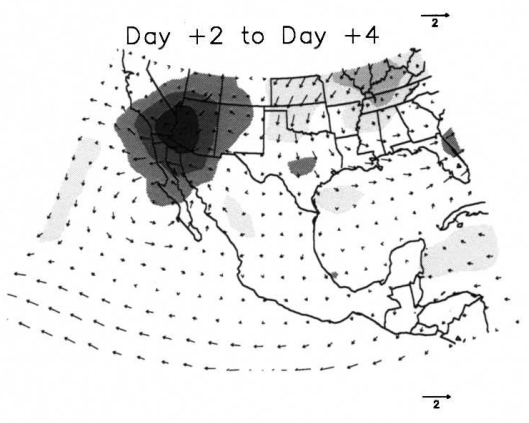

FIG. 5. Composite evolution of 700-hPa specific humidity anomalies $\left(\mathrm{g} \mathrm{kg}^{-1}\right)$ and vector wind anomalies ( $\left.\mathrm{m} \mathrm{s}^{-1}\right)$ for (a) all surges, (b) TC-related surges, and (c) surges not related to TCs. Surges are keyed to Yuma: day 0 is the onset date of the surges. The averaging period relative to onset is indicated in each panel. The shading intervals for specific humidity anomalies are given by the color bar while the standard vector length for vector wind anomalies is $2 \mathrm{~m} \mathrm{~s}^{-1}$. The number of cases in each composite is given in Table 1.

Moisture transport is generally from the south and east for both the direct and indirect cases (Fig. 6), with much of the moisture originating in the deep Tropics. However, in the direct cases there is considerably more transport along the GOC than in the indirect cases. The direct cases also entrain moisture from the southwestern Gulf of Mexico (Fig. 6a). The differences between direct and indirect cases (Fig. 6c) emphasize the relative increase in easterly flow and moisture in the southwest United States for the direct cases.

The composite evolution of $200-\mathrm{hPa}$ vector wind anomalies shows an anticyclonic anomaly over the western United States during and after onset for the composite based on all surges (not shown). The composite shows strong northeasterly (and diffluent) flow over the southwestern United States and northwestern Mexico. The anticyclonic circulation feature is stronger and shifted to the southwest for the TC-related surges, reflecting the strong upper-level divergence and anticyclonic circulation typically located directly over the TCs. The anticyclonic anomaly discussed above is somewhat stronger and closer to the west coast of North America for the direct cases and farther from the coast for the indirect cases.

\section{c. Propagation speed}

Time-latitude sections of the composite mean 925$\mathrm{hPa}$ meridional wind anomalies at along-gulf locations (i.e., grid points with latitude and longitude coordinates along the GOC between $20^{\circ} \mathrm{N}, 107^{\circ} \mathrm{W}$ and $32^{\circ} \mathrm{N}$, $114^{\circ} \mathrm{W}$ ) were used to obtain estimates of the average propagation rates of surge events. Results for Yuma surges with direct, indirect, and no relationship to TCs are shown in Figs. 7a-c. For reference, we also show time series of sea level pressure differences between a southern GOC location [Mazatlan $\left(23.2^{\circ} \mathrm{N}, 106.4^{\circ} \mathrm{W}\right)$ ] 
(a) Direct
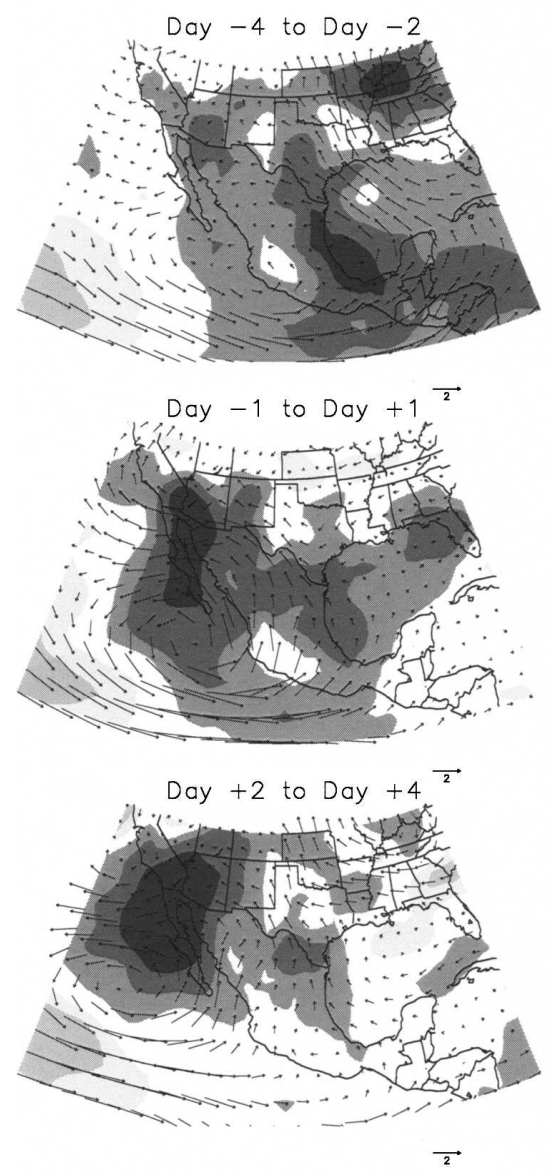

(b) Indirect
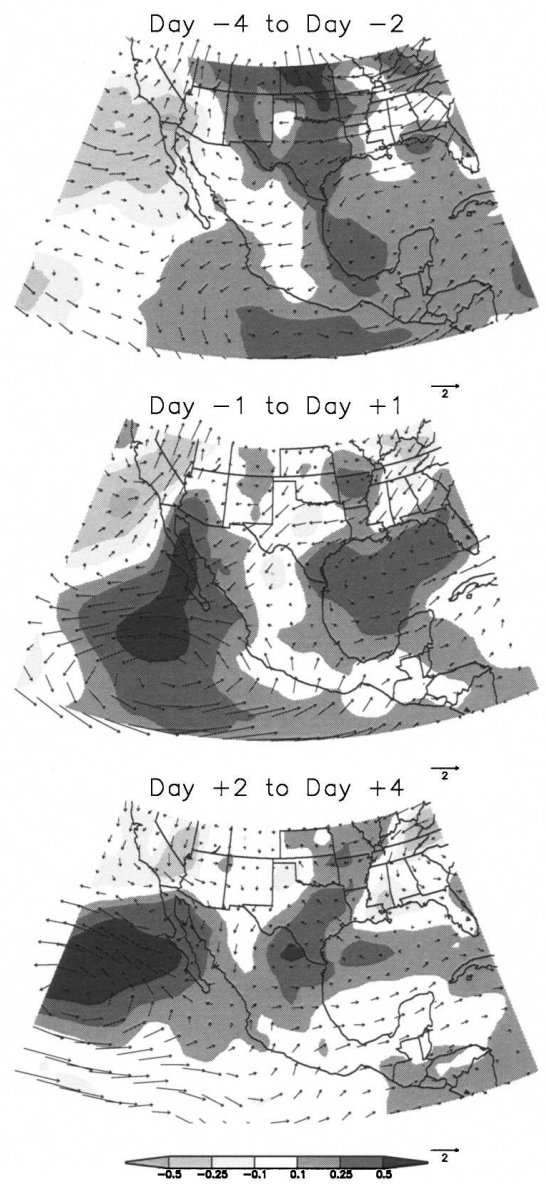

(c) Direct-Indirect
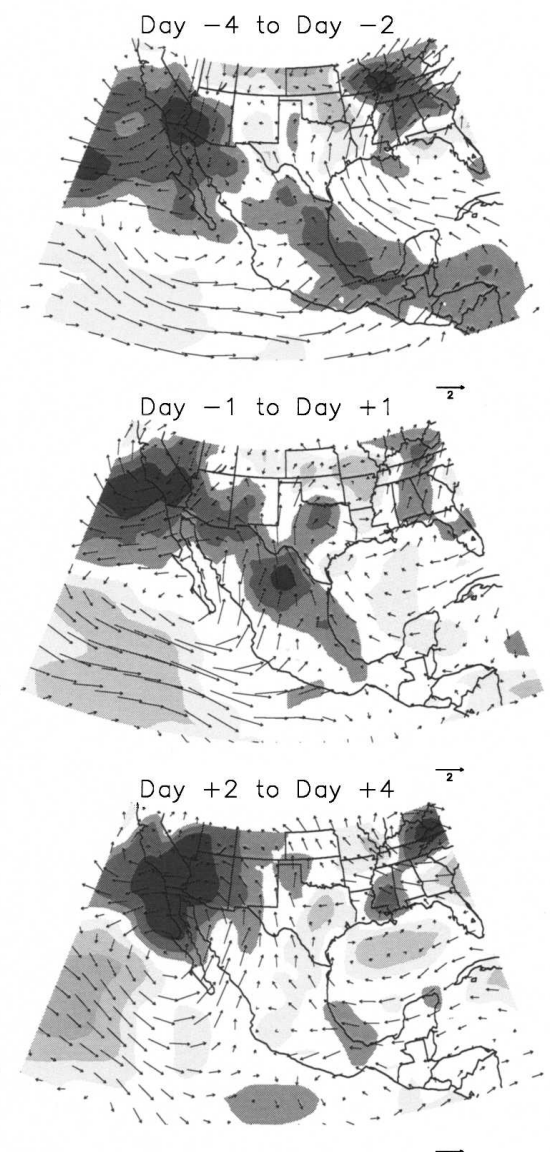

FIG. 6. As in Fig. 5, but for Yuma surges with (a) direct, (b) indirect, and (c) direct - indirect relationships to TCs.

and a northern GOC location [Yuma $\left(32.5^{\circ} \mathrm{N}, 114.0^{\circ} \mathrm{W}\right)$ ] to illustrate the evolution of the pressure jumps discussed in the previous subsection (Figs. 7d-f).

The average propagation speeds of the surge events between southern and northern GOC locations (indicated in the figure) are approximately $10 \mathrm{~m} \mathrm{~s}^{-1}$ in each composite (Figs. 7a-c), with no discernable difference between the composites. The composite mean rates are roughly 2.5 times slower than those measured during NAME IOP 2 (Johnson et al. 2004). An examination of the individual cases in the composites indicates that the propagation rates are always less than that observed in the NAME case during July 2004. Stensrud et al. (1997) found that modeled surges move northward at 10-23 $\mathrm{m} \mathrm{s}^{-1}$ and typically slow down with time. However, these rates were obtained from a mesoscale model with higher vertical $(\sim 50 \mathrm{~m})$ and temporal (at least 3 hourly) resolution than in the Regional Reanalysis, suggesting that spatial and temporal resolution could be a factor limiting the propagation rates in our results. We note that the slower propagation speeds may also be due to the lack of assimilated data along the GOC. NAME data impact studies currently in progress using the same assimilation system used to produce the Regional Reanalysis may help to address this question (K. Mo 2005, personal communication).

Southerly meridional wind anomalies are largest and have the longest duration for the direct cases, consistent with the stronger meridional moisture transport along the GOC (Fig. 7a). Yuma surges that are not related to TCs appear to be confined to the central and northern GOC locations (Fig. 7c), indicating that they are primarily in response to regional disturbances (e.g., shallow mesoscale convective system outflows, upperlevel inverted troughs moving across central Mexico, etc.).

Time series of the sea level pressure difference between Mazatlan and Yuma indicate relative increases in pressure in the southern GOC over a 2-day period prior to onset. Average differences are as large as $2 \mathrm{hPa}$ in the direct cases at day 0 (Fig. $7 \mathrm{~d}$ ), but only $1 \mathrm{hPa}$ in the 

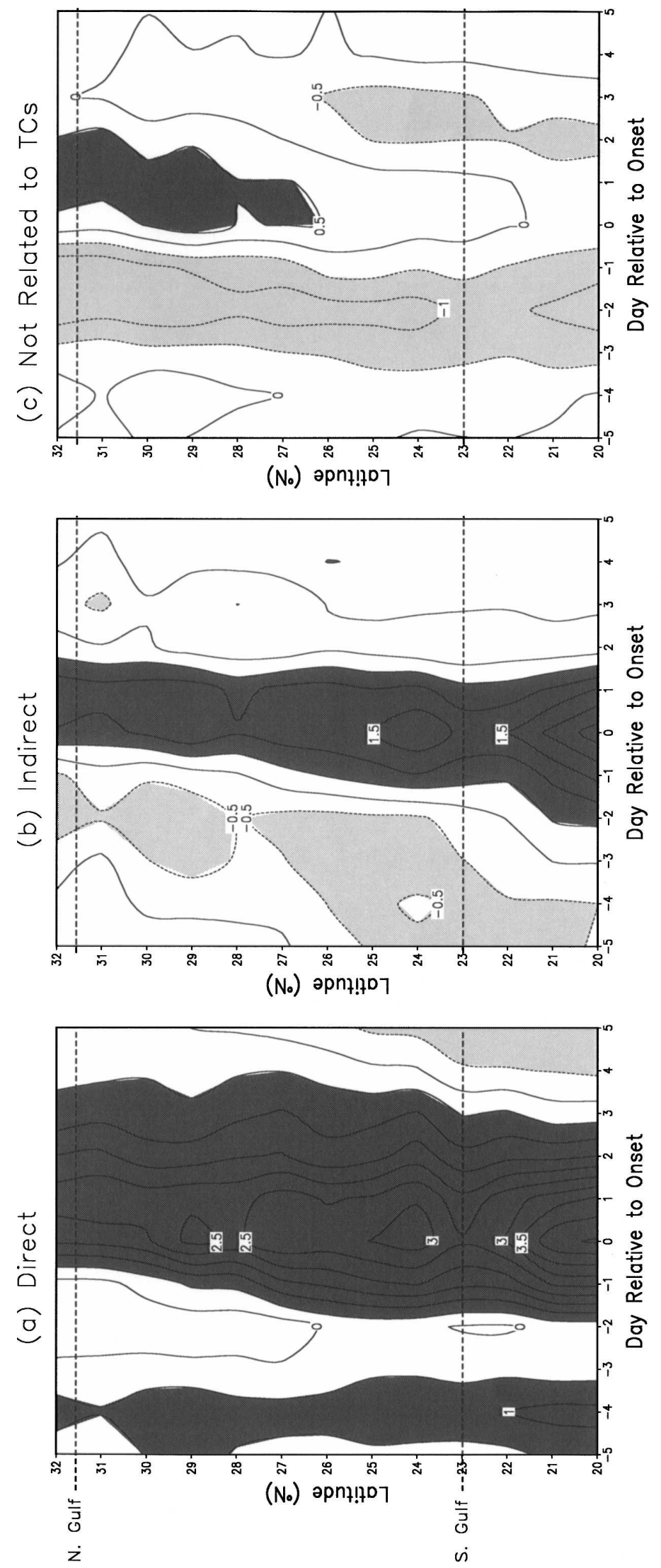

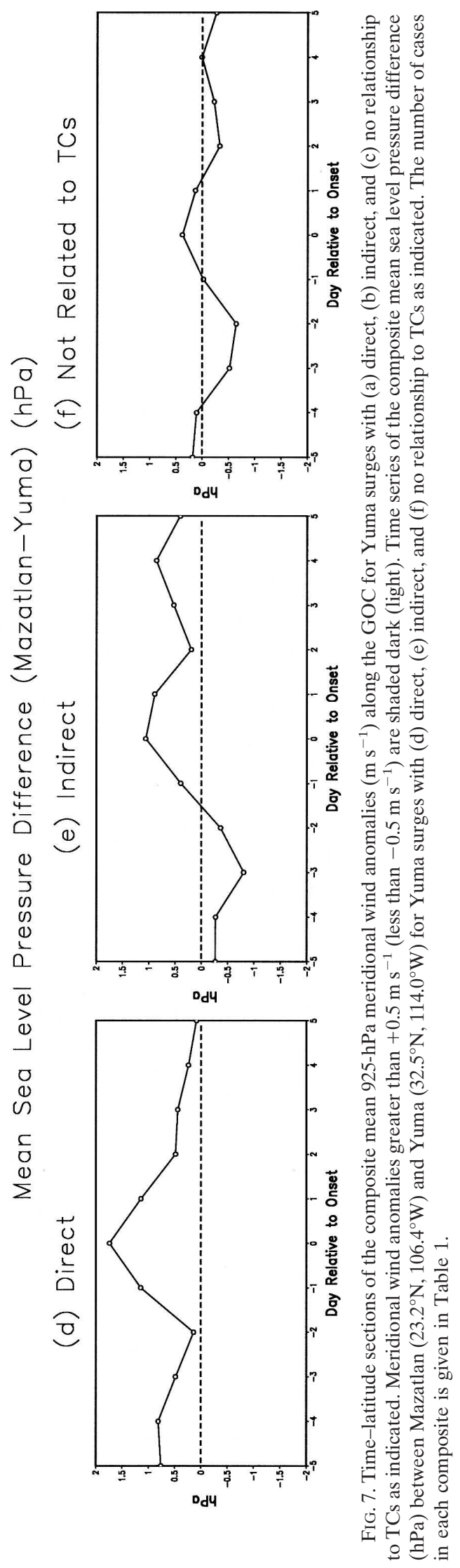


(a) TC-Related
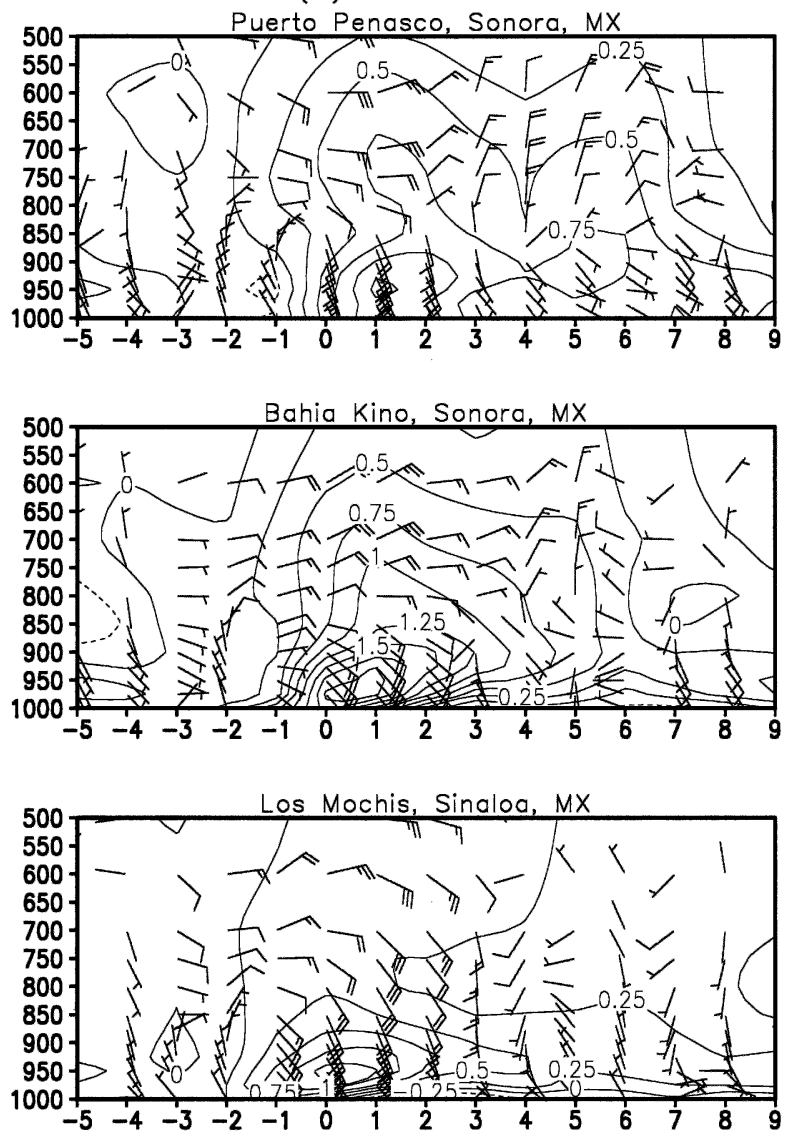

Day Relative to Onset (b) Not Related to TCs
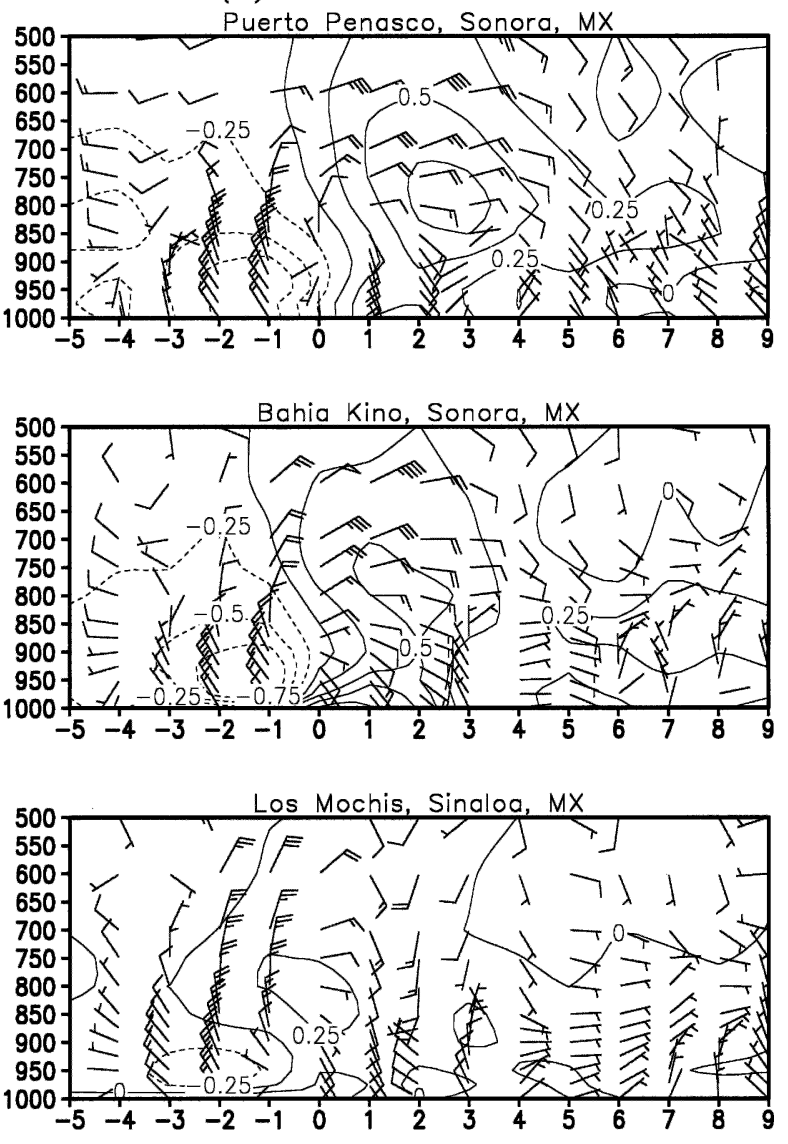

Day Relative to Onset

FIG. 8. Composite evolution of vertical profiles of wind direction and wind speed anomalies (tenths of knots) and specific humidity anomalies $\left(\mathrm{g} \mathrm{kg}^{-1}\right)$ at Puerto Penasco $\left(32^{\circ} \mathrm{N}, 114^{\circ} \mathrm{W}\right)$, Bahia Kino $\left(32^{\circ} \mathrm{N}, 112^{\circ} \mathrm{W}\right)$, and Los Mochis $\left(26^{\circ} \mathrm{N}, 109^{\circ} \mathrm{W}\right)$, for (a) TC-related moisture surges and (b) surges not related to TCs. Anomalies are departures from base period (July-August 1979-2001) mean daily values. Wind barbs are used and wind barb flags are shown in tenths of knots $\left(1 \mathrm{~m} \mathrm{~s}^{-1}=1.9 \mathrm{kt}\right)$ where half a barb flag is $0.5 \mathrm{kt}$ and a full-barb flag is $1.0 \mathrm{kt}$. The wind barbs point in the direction the wind anomalies are blowing from (e.g., the barbs point upward for southerly winds, etc.). The number of cases in each composite is given in Table 1.

indirect cases (Fig. 7e) and only $0.5 \mathrm{hPa}$ in the cases with no relationship to TCs (Fig. 7f).

\section{d. Wind and moisture profiles}

The temporal evolution of vertical profiles of the wind and moisture anomalies are shown for each category of surge event in Figs. 8 and 9. Results are shown at northern, central, and southern GOC locations near Puerto Penasco $\left(32^{\circ} \mathrm{N}, 114^{\circ} \mathrm{W}\right)$, Bahia Kino $\left(29^{\circ} \mathrm{N}\right.$, $\left.112^{\circ} \mathrm{W}\right)$, and Los Mochis $\left(26^{\circ} \mathrm{N}, 109^{\circ} \mathrm{W}\right)$, respectively, to coincide with locations of wind profilers during the NAME 2004 field campaign (Higgins et al. 2004b).

The TC-related surges (Fig. 8a) have stronger lowlevel southerly flow and larger increases in moisture along the GOC than surges not related to TCs (Fig. 8b).
Maximum southerly wind anomalies are much weaker and less coherent for the Yuma surges that are not related to TCs (Fig. 8b).

The TC-related surges have easterly anomalies at midtropospheric levels at all three locations during and after onset (Fig. 8a), while surges not related to TCs have easterly anomalies in the central and northern GOC (Fig. 8b). The largest moisture anomalies are confined below $850 \mathrm{hPa}$ in the TC-related composites (Fig. 8a) and the anomalies tend to persist for a longer time after onset at the northern sites. Overall, the evolution is much more coherent for Yuma surges related to TCs.

Surges that are directly related to TCs have stronger low-level southerly flow and the most significant increases in moisture along the GOC (Fig. 9a). Peak southerly wind anomalies typically occur within a day 
(a) Direct
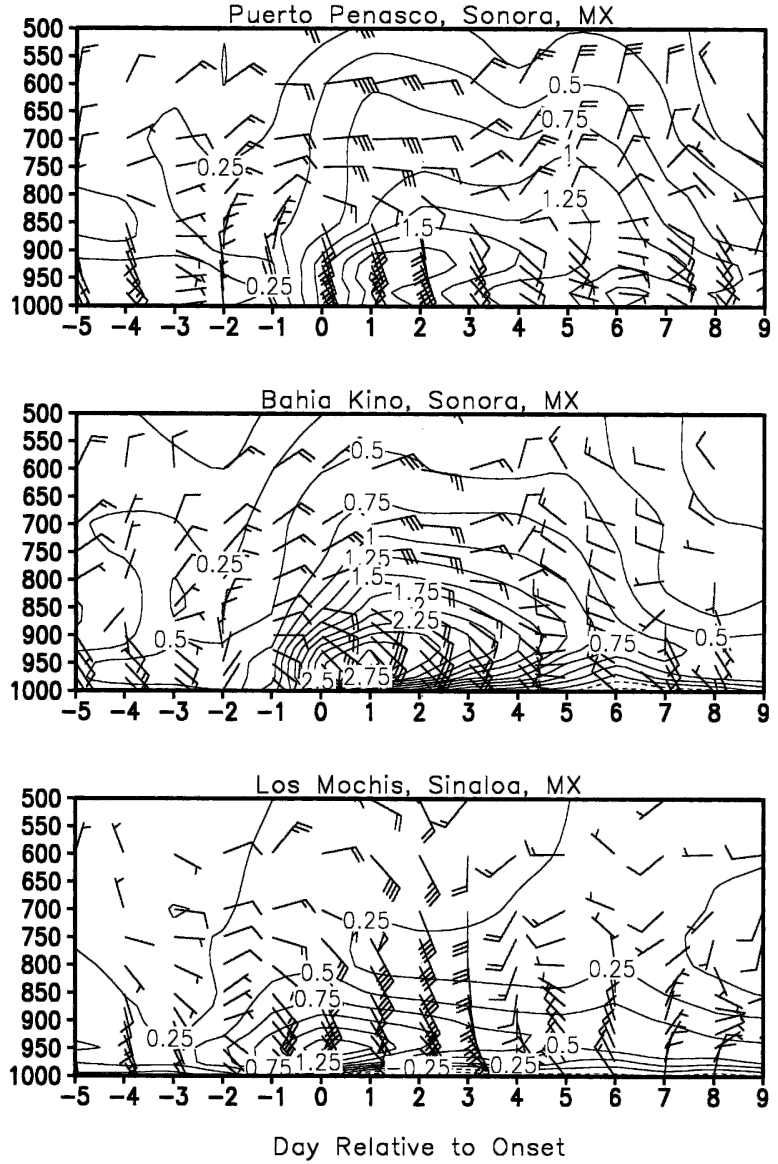

(b) Indirect
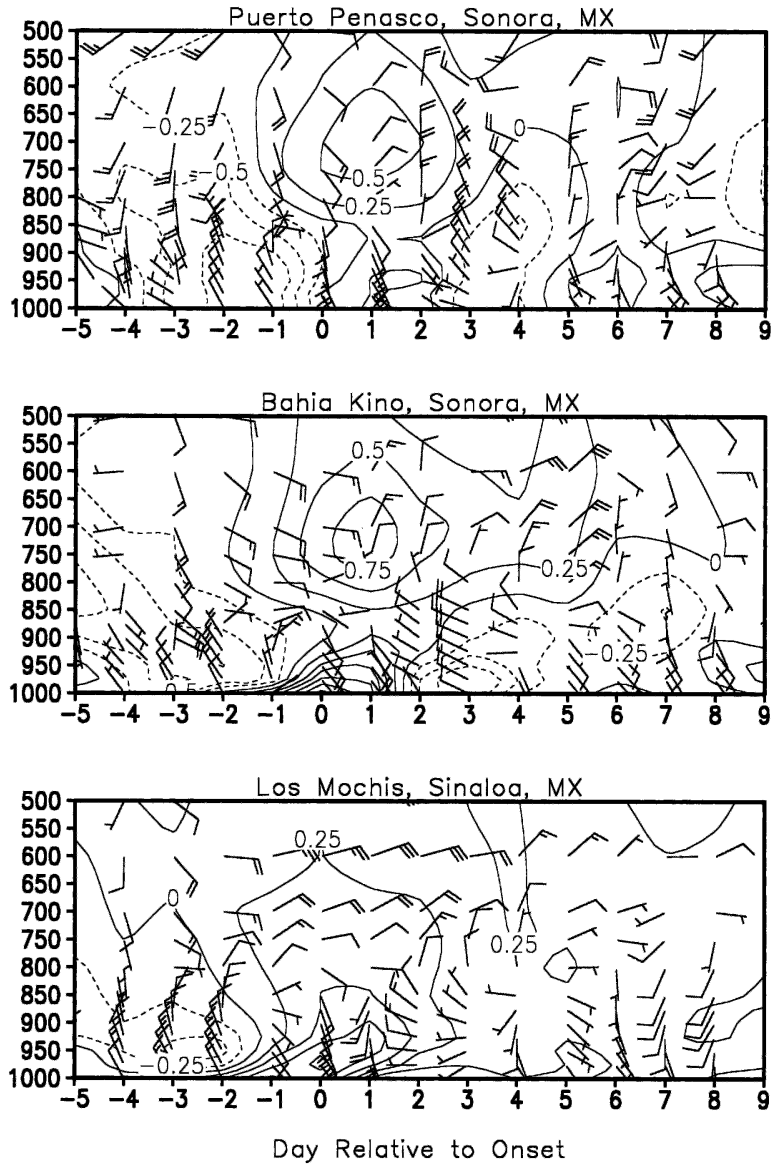

FIG. 9. As in Fig. 8, but for Yuma surges with (a) direct and (b) indirect relationships to TCs.

of onset near 900-950 hPa (approximately $1 \mathrm{~km}$ above the ground) at all three locations for TC-related surges (Fig. 9a). These events provide abundant low-level moisture to the Arizona-New Mexico (AZNM) region, leading to significant rains during and after onset (see section $4 \mathrm{e}$ ). For surges directly related to TCs, the specific humidity anomalies are as large as $25 \%$ of the mean value at Puerto Penasco (Fig. 9a). Deep easterly flow is present at midlevels both during and after onset at Bahia Kino and Puerto Penasco.

\section{e. Precipitation patterns}

The composite evolution of observed daily precipitation anomalies over Mexico and the conterminous United States for all surges keyed to Yuma (Fig. 10a) shows a southeast-to-northwest progression of positive precipitation anomalies along the west coast of Mexico toward Arizona. Just prior to onset the conditions are drier than normal in northwestern Mexico and wetter than normal in southeastern Mexico. During onset positive anomalies span the west coast of Mexico. After onset positive anomalies are found in northwest Mexico and Arizona.

The magnitude and areal extent of the anomalies increase considerably for TC-related surges (Fig. 10b) when compared to those that are not related to TCs (Fig. 10c). Positive precipitation anomalies are much larger and more widespread over Mexico for the TCrelated surges (Fig. 10b). The composite evolution for surges not related to TCs is dominated by negative anomalies over most of Mexico and the southwestern United States except in the immediate vicinity of the surge in the GOC region.

The composites in Fig. 10 show strong evidence of westward propagation over Mexico and the southwestern United States, consistent with a strong relationship between the gulf surges, precipitation, and westwardpropagating tropical disturbances. The composites in Fig. 10b confirm the relationship between Yuma surges and TCs. Other types of disturbances (tropical easterly 
(a) All
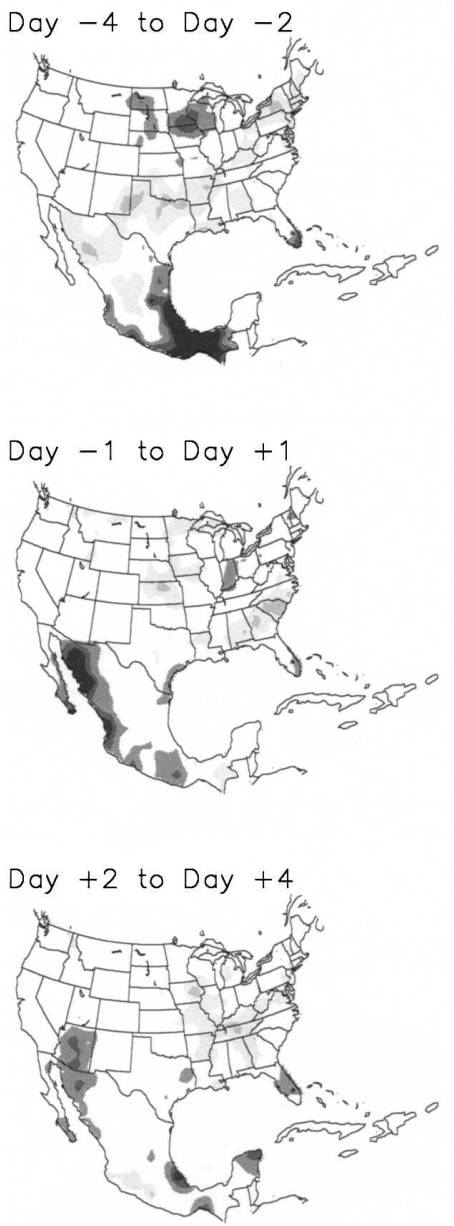

(b) TC-Related
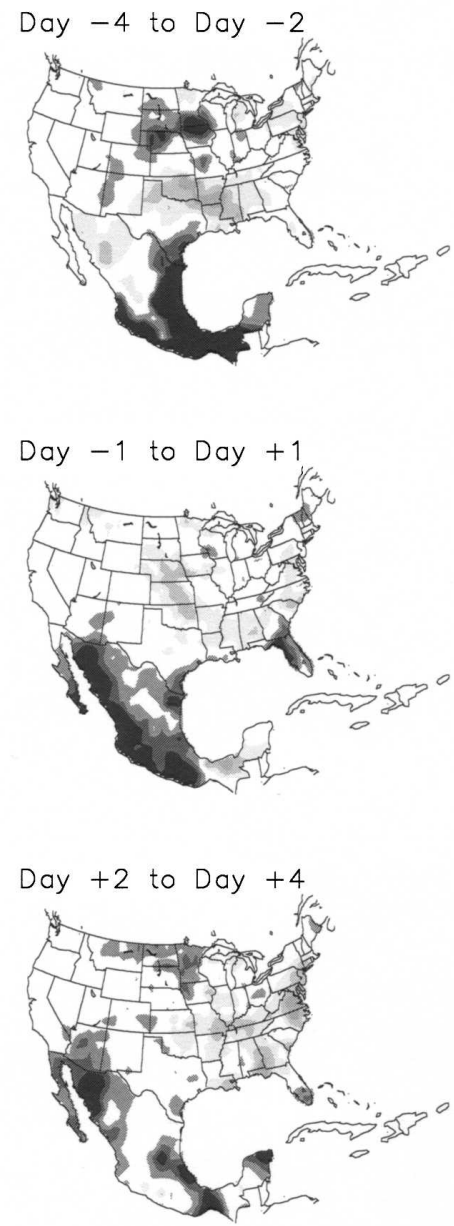

(c) Not Related to TCs
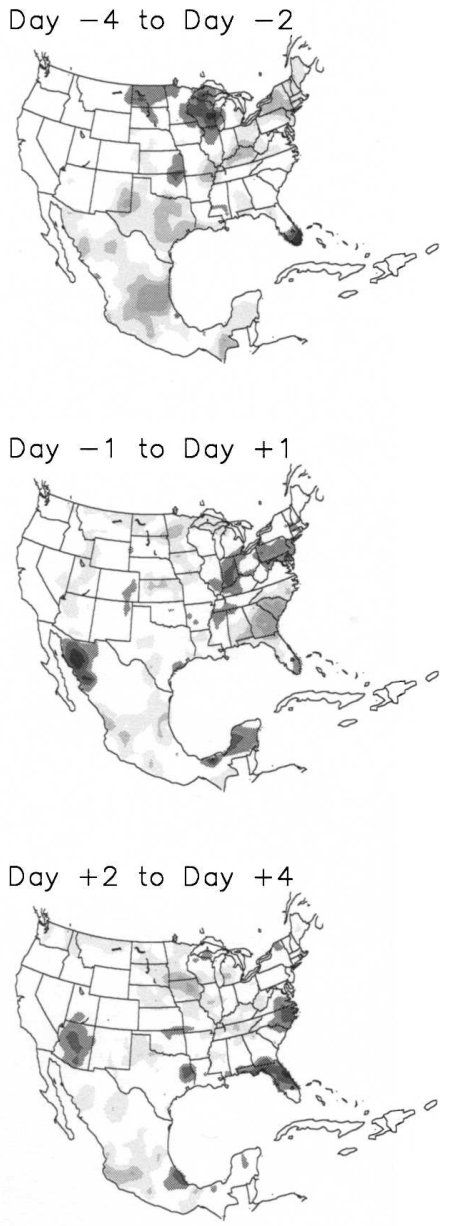

FIG. 10. Composite evolution of accumulated precipitation anomalies (mm) for (a) all surges, (b) TC-related surges, and (c) surges not related to TCs. Surges are keyed to Yuma: day 0 is the onset date of the surges. The accumulation period relative to onset is indicated in each panel. The shading interval is $1 \mathrm{~mm} \mathrm{day}^{-1}$ and values greater than $1 \mathrm{~mm}$ day $^{-1}$ (less than $-1 \mathrm{~mm}^{-1 a y}{ }^{-1}$ ) are shaded dark (light). The number of cases in each composite is given in Table 1 .

waves, upper-level inverted troughs) are also likely to be important, as indicated by the cases that are not related to TCs (Fig. 10c), but they do not appear to have as large an impact on the precipitation pattern as the TCs. We note, however, that the non-TC-related composite fields may be weaker because the timing of the precipitation with respect to the surge passage varies with the type of disturbance. Additional investigation of the individual cases in the non-TC-related composite is needed to quantify the influence of the different types of disturbances on the precipitation pattern.

The westward propagation of the precipitation anomaly pattern presented in Fig. 10 is consistent with previous studies (e.g., Stensrud et al. 1997; Fuller and Stensrud 2000; Higgins et al. 2004a) that have discussed relationships between surge onset at Yuma and the passage of tropical easterly wave troughs from east to west across Mexico during the period just prior to surge onset.

The composites in Fig. 10b were divided into direct (Fig. 11a) and indirect cases (Fig. 11b). The composites for surges that are directly related to TCs (Fig. 11a) show a southeast-to-northwest progression of large positive anomalies over virtually all of Mexico just prior to onset, and Arizona after onset. The composites for cases that are indirectly related to TCs (Fig. 11b) show 
(a) Direct
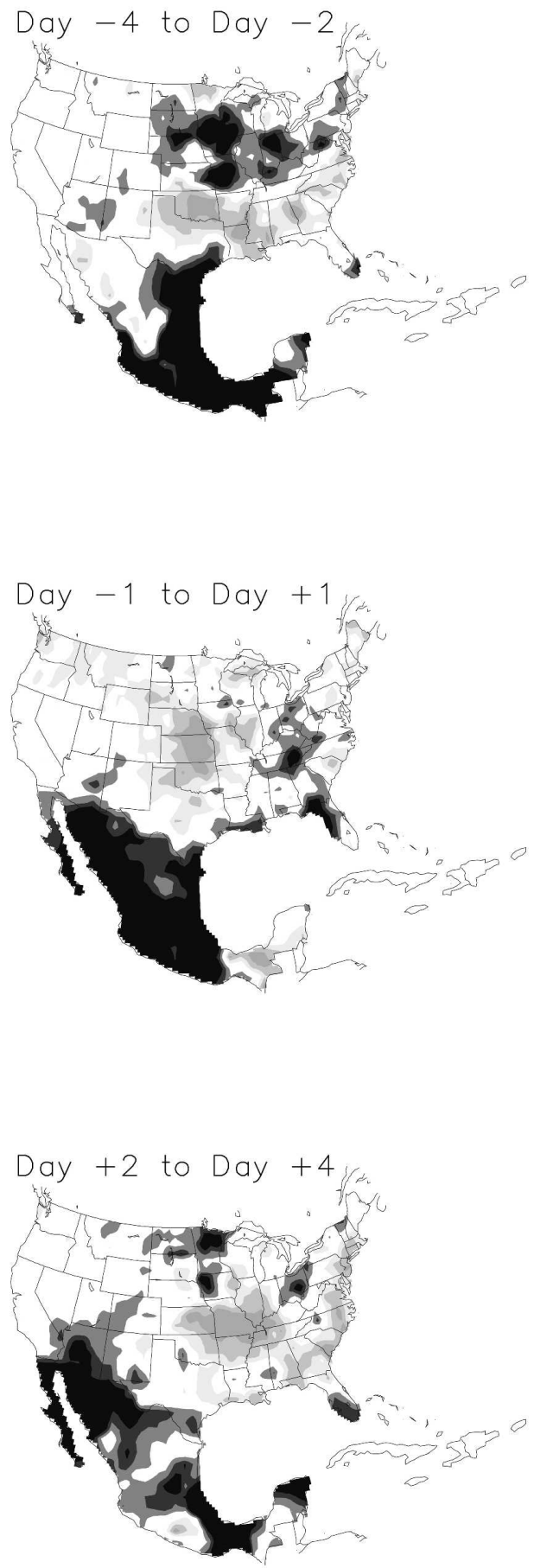

(b) Indirect
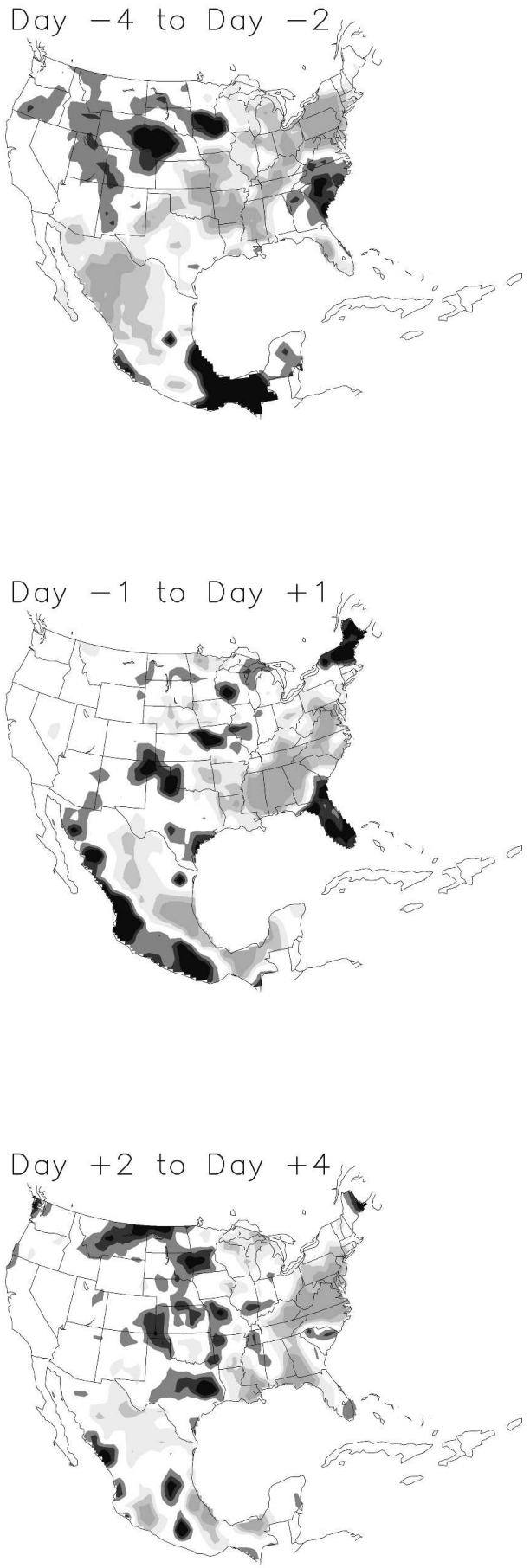
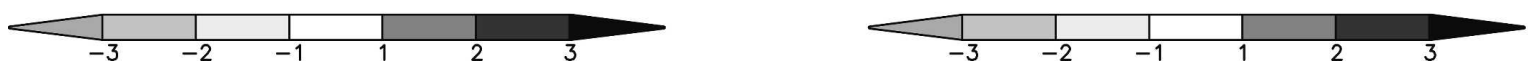

FIG. 11. As in Fig. 10, but for Yuma surges with (a) direct and (b) indirect relationships to TCs. 
TABLE 5. Area-mean accumulated precipitation anomalies $(\mathrm{mm})$ for (a) the 5-day period (day -5 to day -1 ) prior to the onset of moisture surges keyed to Yuma and for (b) the 5-day period (day 0 to day +4 ) following the onset of moisture surges keyed to Yuma. Results are for all, TC-related, not TC-related, direct, and indirect cases as defined in the text. The number of cases used to compute the area means are given in Table 1.

\begin{tabular}{|c|c|c|c|c|c|}
\hline \multicolumn{6}{|c|}{ (a) Day -5 to day -1} \\
\hline Region & $\begin{array}{c}\text { All } \\
\text { surges }\end{array}$ & $\begin{array}{l}\mathrm{TC} \\
\text { related }\end{array}$ & $\begin{array}{l}\text { Not TC } \\
\text { related }\end{array}$ & Direct & Indirect \\
\hline AZNM & -0.43 & 0.38 & -1.14 & 0.44 & 0.30 \\
\hline Mexico & 0.36 & 2.61 & -1.61 & 5.03 & -0.90 \\
\hline United States & -0.12 & 0.73 & -0.87 & 1.55 & -0.45 \\
\hline \multicolumn{6}{|c|}{ (b) Day 0 to day +4} \\
\hline AZNM & 0.82 & 1.23 & 0.47 & 1.69 & 0.57 \\
\hline Mexico & 0.50 & 1.97 & -0.79 & 3.76 & -0.63 \\
\hline $\begin{array}{l}\text { United States } \\
\text { and Mexico }\end{array}$ & -0.29 & 0.11 & -0.64 & 0.53 & -0.50 \\
\hline
\end{tabular}

positive anomalies along the west coast of Mexico and negative anomalies farther to the east throughout the evolution, consistent with the location of these TCs farther to the south and west.

The results in Figs. 10 and 11 clearly demonstrate that GOC moisture surges are associated with significant changes in the precipitation pattern over Mexico and portions of the southwestern United States during their evolution. More significantly, the greatest enhancements in precipitation occur when the surges are directly related to TCs in the eastern tropical Pacific.

It is worth checking to what extent the surges are accompanied by a net increase or decrease in the amount of precipitation and how this varies when TCs are present. Clearly this also depends on the region under consideration. Area mean precipitation anomalies from the composites in Figs. 10 and 11 for the period prior to onset (day -5 to day -1 ) and after onset (day 0 to day +4 ) are given in Table 5 for AZNM, Mexico, and the United States and Mexico combined.

Prior to surge onset at Yuma, the TC-related cases are associated with relatively small positive precipitation anomalies in AZNM that are probably not significant. On the other hand, the positive precipitation anomalies in Mexico are large, consistent with the idea that the heaviest precipitation occurs in the days just prior to surge onset at Yuma. During and after surge onset at Yuma, the TC-related surges are associated with large positive precipitation anomalies in AZNM and relatively smaller positive precipitation anomalies in Mexico. Similar results are obtained for TC-related surges with a direct relationship to TCs. Table 5 also shows that surges not related to TCs are associated with anomalously dry conditions, except in AZNM after onset.

It is also interesting to consider the fraction (in percent) of total July-August precipitation associated with Yuma surges. To determine this, we accumulated rainfall for the 5-day period (day 0 to day +4 ) following surge onset at Yuma and expressed the results as a fraction of the climatological mean July-August precipitation (using a July-August 1979-2001 base period) to arrive at a percentage in a typical year. Accumulated precipitation anomalies $(\mathrm{mm})$ during a typical JulyAugust associated with these events were also computed.

In a typical July-August there are about six Gulf surge events (132 events over $22 \mathrm{yr}$ ). If precipitation is accumulated for the 5-day period after onset (day 0 to day +4$)$, then slightly less than half $(48 \%)$ of the days during July-August are included in a composite based on all surges. When precipitation is accumulated in this manner for all surge events, we find that more than $60 \%$ of the July-August rainfall occurs over a substantial portion of the core monsoon region and between $50 \%$ and $60 \%$ is observed over all of southwestern North America (Fig. 12a). Over portions of northwestern Mexico and southern Arizona, the accumulated precipitation anomalies exceed $25 \mathrm{~mm}$ per July-August (Fig. 12d). It is also interesting to note that precipitation is lighter than during nonsurge periods over much of the central and eastern United States.

The TC-related surges (Fig. 12b) account for a larger fraction of July-August rainfall than surges not related to TCs (Fig. 12c). It is important to note that the accumulated rainfall in Figs. $12 \mathrm{~b}$ and $12 \mathrm{c}$ sums exactly to that in Fig. 12a. The TC-related surges (Fig. 12b) account for between $30 \%$ and $50 \%$ of July-August precipitation in northwestern Mexico and southern Arizona, depending on the location. Since the TC-related cases account for $49 \%$ of all surge cases, this implies that only $23 \%$ of the July-August days are included in the day 0 to day +4 surge composites. Thus, $23 \%$ of the July-August days account for $30 \%-50 \%$ of the total precipitation accumulation depending on the location. For the TC-related cases, accumulated precipitation anomalies exceeding $15 \mathrm{~mm}$ are found along coastal regions of northwestern Mexico and in southern Baja California (Fig. 12e). Alternately, surges not related to TCs (Fig. 12c) account for generally less than $30 \%$ of July-August precipitation in the Southwest. Accumulated precipitation anomalies for surges not related to TCs (Fig. 12f) are relatively small compared to those for TC-related cases (Fig. 12e). 


\section{Fraction (\%) of Total Precipitation Accumulated Precipitation Anomaly (mm) (Day 0 to Day +4) \\ (Day 0 to Day +4)}
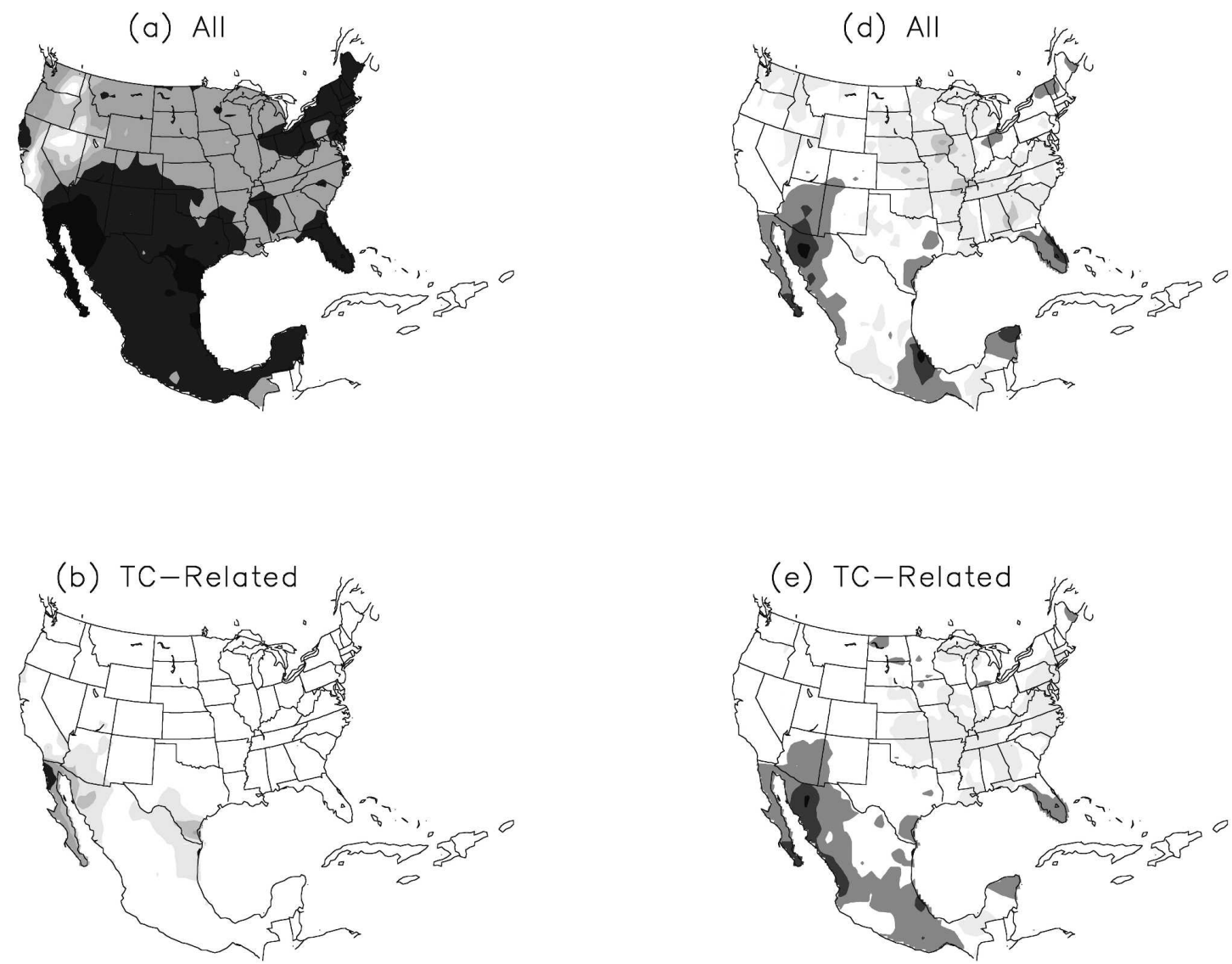

(c) Not Related to TGs.

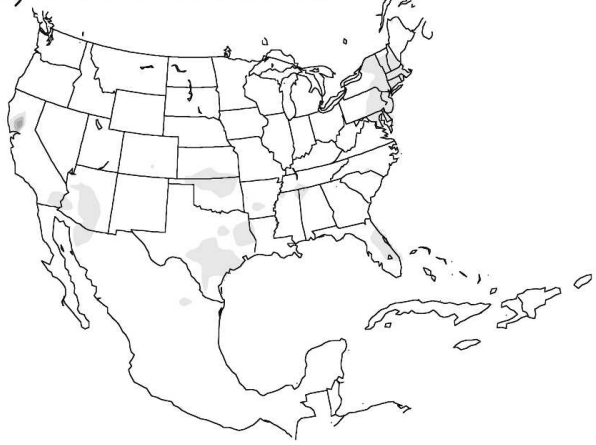

(f) Not Related to TGs.
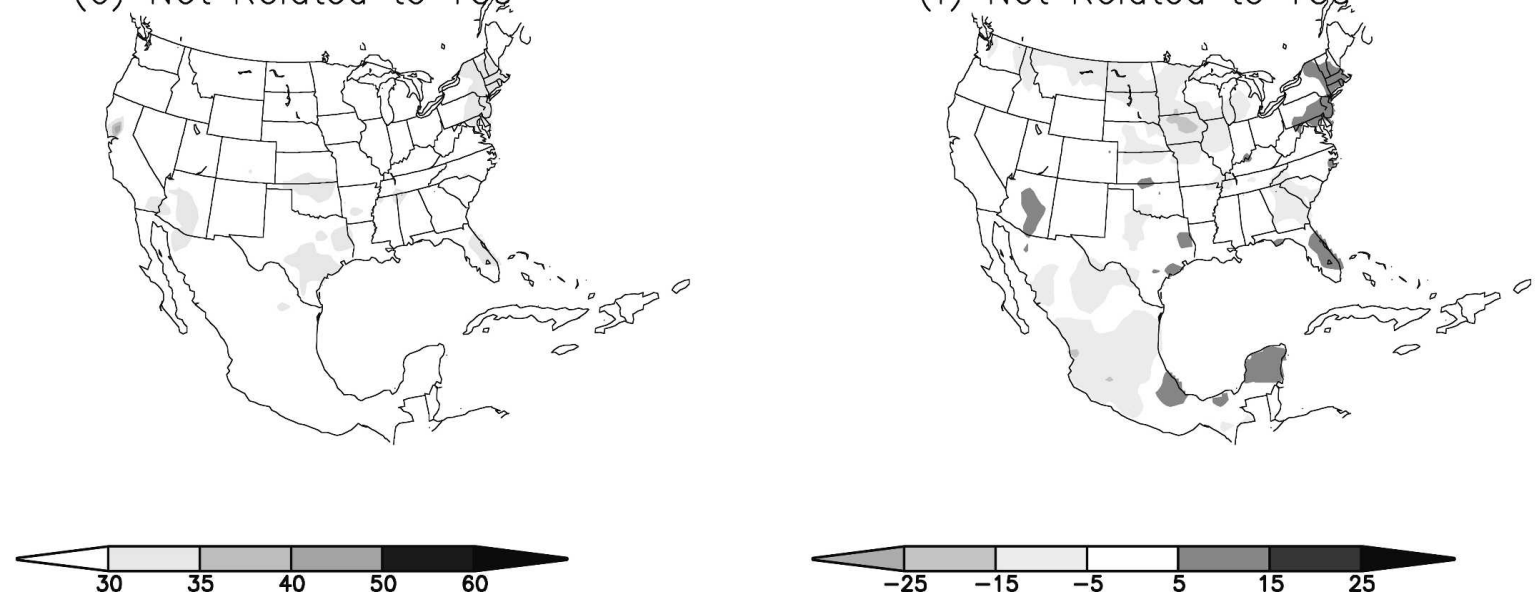

FIG. 12. Fraction (in percent) of total July-August precipitation associated with Yuma surges for (a) all surges, (b) TC-related surges, and (c) surges not related to TCs. Results are based on the period during and after onset of Yuma surges (day 0 to day +4$)$ and are expressed as a fraction of the climatological mean July-August 1979-2001 precipitation. Accumulated precipitation anomalies (mm) during a typical July-August associated with Yuma surges for (d) all surges, (e) TC-related surges, and (f) surges not related to TCs. Anomalies are departures from base period July-August 1979-2001 means. 


\section{Fraction (\%) of Total Precipitation (Day 0 to Day +4 )}
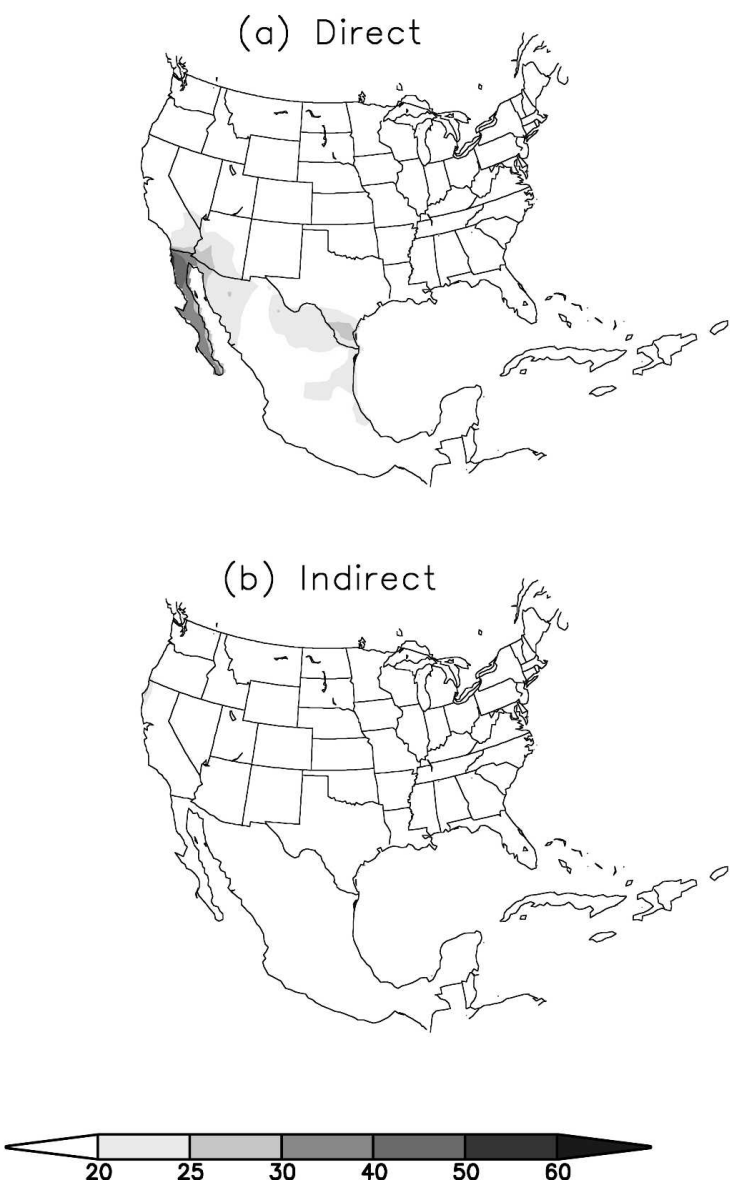

\section{Accumulated Precipitation Anomaly $(\mathrm{mm})$} (Day 0 to Day +4 )
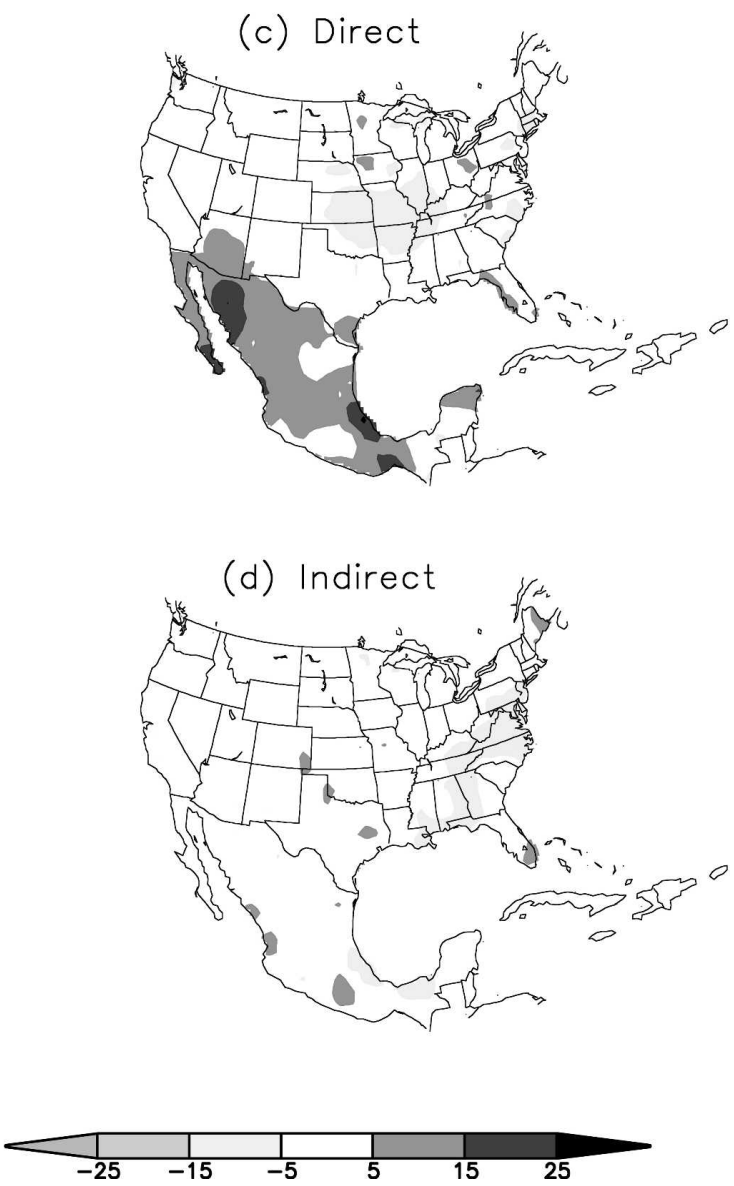

FIG. 13. As in Fig. 12, but during Yuma surges with (a), (c) direct and (b), (d) indirect relationships to TCs.

The fraction of summer rainfall that accumulates during TC-related surges (Fig. 12b) was partitioned into that which occurs for direct (Fig. 13a) and indirect (Fig. 13b) cases. Direct cases account for most of the accumulated precipitation (Fig. 13a) and accumulated precipitation anomalies (Fig. 13c) during TC-related surge events, while indirect cases account for much less (Figs. 13b and 13d).

The composites of the previous five subsections confirm many of the characteristics of the circulation, moisture, and precipitation patterns noted by Johnson et al. (2004) in the NAME 2004 IOP 2 case study. Clearly there is a need to examine the individual cases in the composites more carefully in an effort to sort out the potential mechanisms involved (e.g., Zehnder 2004).

\section{Summary}

Relationships between moisture surges in the Gulf of California and tropical cyclones in the eastern North Pacific basin were examined. Emphasis was placed on the relative differences in the atmospheric circulation, moisture, and precipitation patterns for several categories of surge event keyed to Yuma, Arizona, including surges that were TC related, not TC related, direct, and indirect.

Several characteristics of the atmospheric circulation, moisture and precipitation patterns observed during NAME IOP 2 were examined in the composites. These characteristics included the pressure gradient in the GOC region, vertical profiles of the wind and moisture fields, and the associated precipitation patterns. The 
TC-related composites reproduced the basic features found in observations, especially for cases with a direct relationship to the Yuma surges. The TC-related surges account for slightly less than half of all surges. On average, Yuma surges with a direct relationship to TCs occur 1.5 times per year and are associated with the heaviest rainfall.

We note that there is no statistically significant relationship between ENSO phase and the frequency of surge events, though this may be due to the insufficient number of ENSO events during the period analyzed here (1979-2001).

The surge characteristics in the composites are weaker than those observed in the NAME IOP 2 case study, so it will be important to examine the case-tocase variability in the composites in more detail, in particular to identify how the synoptic disturbances relate to the particular mechanisms. This is especially true for the Yuma surges with no relationship to TCs, as they are often confined to the northern portion of the GOC, implying that different mechanisms are at work. In addition, there is some sensitivity to the definition used to identify direct and indirect cases, so this should be investigated systematically.

The NAME 2004 sounding and profiler data are expected to reveal additional insight into the dynamics of surges. In particular, they will be used to help evaluate proposed mechanisms (e.g., Zehnder 2004). Johnson et al. (2004) have suggested that the surge during NAME IOP2 had the characteristics of an atmospheric bore (propagation rates on the order of $25 \mathrm{~m} \mathrm{~s}^{-1}$ ), but it remains to be determined if this is common. The data will also be used to produce high-resolution atmospheric analyses for NAME data impact studies (e.g., analyses with and without NAME 2004 data) that identify the influence of the regional circulation and moisture patterns on the larger-scale patterns during the surge events. This will include studies of the influence of the leading patterns of climate variability (such as the Madden-Julian oscillation) on the TC-surgeprecipitation relationships. Finally, the NAME 2004 data will be used by the global and regional modeling communities to evaluate our ability to simulate (and ultimately predict) the characteristics of surges, such as those emphasized here. It is hoped that this study has shed some light on the ability of state-of-the-art atmospheric analyses to capture these features.

Acknowledgments. We gratefully acknowledge Will Spangler for assistance in accessing the hourly surface observations used in this study. We also thank Miguel Cortez for providing us with daily precipitation data for Mexico. Thanks are extended to Vernon Kousky,
David Stensrud, and Richard Johnson for insightful comments on this work.

\section{REFERENCES}

Adams, D. K., and A.C. Comrie, 1997: The North American monsoon. Bull. Amer. Meteor. Soc., 78, 2197-2213.

Anderson, B. T., J. O. Roads, and S.-C. Chen, 2000: Large-scale forcing of summertime monsoon surges over the Gulf of California and the southwestern United States. J. Geophys. Res., 105, 24 455-24 467.

Brenner, I. S., 1974: A surge of maritime tropical air-Gulf of California to the southwestern United States. Mon. Wea. Rev., 102, 375-389.

Douglas, M. W., 1995: The summertime low-level jet over the Gulf of California. Mon. Wea. Rev., 123, 2334-2347.

_ flow over the Arizona low desert from SWAMP-1993 observations. Mon. Wea. Rev., 124, 1211-1224.

_ , and J. C. Leal, 2003: Summertime surges over the Gulf of California: Aspects of their climatology, mean structure, and evolution from radiosonde, NCEP reanalyis, and rainfall data. Wea. Forecasting, 18, 55-74.

- R. A. Maddox, K. Howard, and S. Reyes, 1993: The Mexican monsoon. J. Climate, 6, 1665-1677.

Englehart, P. J., and A. V. Douglas, 2001: The role of eastern North Pacific tropical storms in the rainfall climatology of western Mexico. Int. J. Climatol., 21, 1357-1370.

Fawcett, P. J., J. R. Stalker, and D. S. Gutzler, 2002: Multistage moisture transport into the interior of northern Mexico during the North American summer monsoon. Geophys. Res. Lett., 29, 2094, doi:10.1029/2002GL015693.

Fuller, R. D., and D. J. Stensrud, 2000: The relationship between easterly waves and surges over the Gulf of California during the North American monsoon. Mon. Wea. Rev., 128, 29832989.

Gutzler, D. S., and E. A. Ritchie, 2004: Eastern Pacific tropical cyclone development and the North American monsoon system. First Int. CLIVAR Science Conf., Baltimore, MD, World Climate Research Programme/Climate Variability and Predictability Program, Poster MS-57. [Available from CLIVAR Project Office, Suite 250, 1717 Pennsylvania Ave. NW, Washington, DC 20006; also available online at http://www. clivar2004.org/electronic\%20posters/monsoons/2Gutzler. D.MS-57.pdf.]

Hales, J. E., Jr., 1972: Surges of maritime tropical air northward over the Gulf of California. Mon. Wea. Rev., 100, 298-306.

Higgins, R. W., W. Shi, and C. Hain, 2004a: Relationships between Gulf of California moisture surges and precipitation in the southwestern United States. J. Climate, 17, 2983-2997.

, and the NAME Science Working Group, 2004b: The North American Monsoon Experiment (NAME) 2004 Field Campaign, CLIVAR Exchanges, No. 30 (Vol. 9, No. 2), International CLIVAR Project Office, Southampton, United Kingdom.

- W. Shi, E. Yarosh, and R. Joyce, 2000: Improved United States precipitation quality control system and analysis. NCEP/Climate Prediction Center ATLAS 7, 40 pp. [Available from Climate Prediction Center, 5200 Auth Rd., Camp Springs, MD 20746.]

Johnson, R., P. Ciesielski, and P. Rogers, 2004: Preliminary results of the NCAR ISS deployment in NAME. Proc. 29th Climate Diagnostics and Prediction Workshop, Madison, WI, CPC 
and Amer. Meteor. Soc. [Available online at http://cpc.ncep. noaa.gov/products/outreach/proceedings/cdw29_proceedings/ presentations.shtml, and from Climate Prediction Center, 5200 Auth Rd., Camp Springs, MD 20746.]

Kalnay, E., and Coauthors, 1996: The NCEP/NCAR 40-Year Reanalysis Project. Bull. Amer. Meteor. Soc., 77, 437-471.

Meitin, J. G., K. W. Howard, and R. A. Maddox, 1991: Southwest area monsoon project. Daily operations summary. [Available online at http://www.nssl.noaa.gov/projects/swamp/1990/ swamp90.html.]

Mesinger, F., and Coauthors, 2005: North American regional reanalysis. Bull. Amer. Meteor. Soc., in press.

Neumann, C. J., B. R. Jarvinen, C. J. McAdie, and G. R. Ham- mer, 1999: Tropical Cyclones of the North Atlantic Ocean, 1871-1998. National Climatic Data Center, 206 pp. [Available from National Climatic Data Center, 151 Patton Ave., Asheville, NC 28801.]

Reyes, S., M. W. Douglas, and R. A. Maddox, 1994: El Monzon del suroeste de Norteamerica (TRAVASON/SWAMP). Atmosfera, 7, 117-137.

Stensrud, D. J., R. L. Gall, and M. K. Nordquist, 1997: Surges over the Gulf of California during the Mexican monsoon. Mon. Wea. Rev., 125, 417-437.

Zehnder, J. A., 2004: Dynamic mechanisms of the Gulf surge. $J$. Geophys. Res., 109, D10107, doi:10.1029/2004JD004616. 